\title{
Resuscitating the Globally Ischemic Brain: TTM and Beyond
}

\author{
Melika Hosseini $^{1} \cdot$ Robert H. Wilson ${ }^{1,2} \cdot$ Christian Crouzet $^{1,2} \cdot$ Arya Amirhekmat $^{1} \cdot$ Kevin S. Wei $^{1} \cdot$ Yama Akbari $^{1,2}$
}

Published online: 4 May 2020

(C) The American Society for Experimental NeuroTherapeutics, Inc. 2020

\begin{abstract}
Cardiac arrest (CA) afflicts 550,000 people each year in the USA. A small fraction of CA sufferers survive with a majority of these survivors emerging in a comatose state. Many CA survivors suffer devastating global brain injury with some remaining indefinitely in a comatose state. The pathogenesis of global brain injury secondary to CA is complex. Mechanisms of CAinduced brain injury include ischemia, hypoxia, cytotoxicity, inflammation, and ultimately, irreversible neuronal damage. Due to this complexity, it is critical for clinicians to have access as early as possible to quantitative metrics for diagnosing injury severity, accurately predicting outcome, and informing patient care. Current recommendations involve using multiple modalities including clinical exam, electrophysiology, brain imaging, and molecular biomarkers. This multi-faceted approach is designed to improve prognostication to avoid "self-fulfilling" prophecy and early withdrawal of life-sustaining treatments. Incorporation of emerging dynamic monitoring tools such as diffuse optical technologies may provide improved diagnosis and early prognostication to better inform treatment. Currently, targeted temperature management (TTM) is the leading treatment, with the number of patients needed to treat being $\sim 6$ in order to improve outcome for one patient. Future avenues of treatment, which may potentially be combined with TTM, include pharmacotherapy, perfusion/oxygenation targets, and pre/postconditioning. In this review, we provide a bench to bedside approach to delineate the pathophysiology, prognostication methods, current targeted therapies, and future directions of research surrounding hypoxic-ischemic brain injury (HIBI) secondary to CA.
\end{abstract}

Key Words Global brain injury · hypoxic-ischemic brain injury · cardiac arrest · neuroprognostication · diffuse optical spectroscopy $\cdot$ targeted temperature management

$\begin{array}{ll}\text { Abbreviations } \\ \text { 20-HETE } & \text { hydroxyeicosatetraenoic acid } \\ \text { AAN } & \text { American Academy of Neurology } \\ \text { ACLS } & \text { advanced cardiac life support } \\ \text { AQP4 } & \text { aquaporin } 4 \\ \text { AHA } & \text { American Heart Association } \\ \text { ATP } & \text { adenosine triphosphate } \\ \text { BBB } & \text { blood-brain barrier } \\ \text { BCLS } & \text { basic cardiac life support } \\ \text { BIS } & \text { bispectral index } \\ \text { BP } & \text { blood pressure } \\ \text { CA } & \text { cardiac arrest }\end{array}$

Melika Hosseini and Robert H. Wilson contributed equally to this work.

Yama Akbari

yakbari@uci.edu

1 Department of Neurology, School of Medicine, University of California, Irvine, USA

2 Beckman Laser Institute, University of California, Irvine, USA

\begin{tabular}{|c|c|}
\hline CABG & coronary artery bypass graft \\
\hline $\mathrm{CBF}$ & cerebral blood flow \\
\hline $\mathrm{CCA}$ & common carotid artery \\
\hline $\mathrm{CMRO}_{2}$ & cerebral metabolic rate of oxygen \\
\hline CNS & central nervous system \\
\hline $\mathrm{CO}_{2}$ & carbon dioxide \\
\hline $\mathrm{CPC}$ & cerebral performance category \\
\hline $\mathrm{CT}$ & computed tomography \\
\hline DCS & diffuse correlation spectroscopy \\
\hline $\operatorname{DOS}(\mathrm{I})$ & diffuse optical spectroscopy and imaging \\
\hline EAA & excitatory amino acid \\
\hline EEG & electroencephalography \\
\hline EMG & electromyography \\
\hline EMS & emergency medical services \\
\hline ERC & European Resuscitation Council \\
\hline ESICM & European Society of Intensive Care Medicine \\
\hline GOS & Glasgow Outcome Scale \\
\hline HIBI & hypoxic-ischemic brain injury \\
\hline HIF & hypoxia-inducible transcription factors \\
\hline ICP & intracranial pressure \\
\hline $\mathrm{LDH}$ & lactate dehydrogenase \\
\hline
\end{tabular}




$\begin{array}{ll}\text { LP } & \text { lactate-to-pyruvate } \\ \text { LPS } & \text { lipopolysaccharides } \\ \text { MAP } & \text { mean arterial pressure } \\ \text { MCA } & \text { middle cerebral artery } \\ \text { MFV } & \text { mean flow velocity } \\ \text { MCS } & \text { mental health composite score } \\ \text { MMP } & \text { matrix metalloproteinase } \\ \text { MMSE } & \text { mini-mental state exam } \\ \text { MPTP } & \text { mitochondrial permeability transition pore } \\ \text { MRI } & \text { magnetic resonance imaging } \\ \text { mRS } & \text { modified Rankin Scale } \\ \text { MSE } & \text { myoclonus status epilepticus } \\ \text { NADH } & \text { nicotinamide adenine dinucleotide } \\ \text { NIRS } & \text { near-infrared spectroscopy } \\ \text { NMDA } & \text { N-methyl-D-aspartate } \\ \text { NO } & \text { nitric oxide } \\ \text { NPi } & \text { Neurological Pupil index } \\ \text { NSE } & \text { neuron-specific enolase } \\ \text { NSR } & \text { nonshockable rhythm } \\ \text { OHCA } & \text { out-of-hospital cardiac arrest } \\ \text { PCS } & \text { physical health composite score } \\ \text { PEA } & \text { pulseless electrical activity } \\ \text { PET } & \text { positron emission tomography } \\ \text { PHDs } & \text { prolyl hydroxylase domain proteins } \\ \text { PLR } & \text { pupillary light reflex } \\ \text { ROS } & \text { reactive oxygen species } \\ \text { ROSC } & \text { return of spontaneous circulation } \\ \text { SD } & \text { spreading depolarization } \\ \text { SSEP } & \text { somatosensory evoked potential } \\ \text { SUR } & \text { sulfonylurea receptor } \\ \text { TTM } & \text { targeted temperature management } \\ \text { VF } & \text { ventricular fibrillation } \\ \text { VIS-NIR } & \text { visible to near-infrared } \\ \text { VT } & \text { ventricular tachycardia } \\ \text { WLST } & \text { withdrawal of life-sustaining therapy. } \\ & \end{array}$

\section{Introduction}

Roughly 550,000 people in the USA suffer cardiac arrest (CA) annually [1]. Despite improvements in advanced cardiac life support (ACLS), basic cardiac life support (BCLS), resuscitation protocols, and training, only $11.5 \%$ of out-of-hospital cardiac arrest (OHCA) patients treated by emergency medical services (EMS) survive until hospital discharge [1]. Of those who survive OHCA, fewer than 9\% are discharged from the hospital with a diagnosis of "good functional status" [1].

Poor neurological outcome is common among CA survivors because CA causes hypoxic-ischemic brain injury (HIBI). HIBI is a complex pathophysiological mechanism of brain damage caused by oxygen deprivation, reduction in cerebral perfusion, and cytotoxicity. It is important to use the term "hypoxic" instead of "anoxic" to describe HIBI because 1) complete loss of oxygen is not necessary to cause HIBI, and 2) the ischemic component of HIBI should not be overlooked [2].

Over the past decade, there have been multiple modifications to monitoring and treatment guidelines for HIBI secondary to CA (Fig. 1). In 2006, the American Academy of Neurology (AAN) proposed a set of prognostic guidelines for CA-induced HIBI, consisting of brain stem reflex assessment, myoclonus status epilepticus $24 \mathrm{~h}$ after CA, somatosensory evoked potential (SSEP) 24-72 h after CA, and neuronspecific enolase (NSE) within 24-72 h after CA [3]. In 2015, the European Resuscitation Council/European Society of Intensive Care Medicine (ERC/ESICM) also adopted a multimodal approach and expanded its guidelines to include targeted temperature management (TTM), sedative clearance, and waiting at least $72 \mathrm{~h}$ prior to prognostication to account for delayed neurological recovery [4]. Despite these revised guidelines, development of improved treatments for global cerebral ischemia induced by $\mathrm{CA}$ is still identified internationally by experts as a critical area of unmet clinical need [5].

Accurate prognostication of neurological outcome for CA patients as early as possible is critical for helping clinicians make the most well-informed treatment and patient care decisions. Indeed, deleterious metabolic changes occur within seconds of injury [6] and hemodynamic dysregulation occurs within minutes [7]. However, despite the rapid dynamics of HIBI, many current clinical techniques for brain injury assessment and prognosis are not performed until 24-72 $\mathrm{h}$ after CA $[3,8]$.

Continuous monitoring of cerebral changes during CAinduced HIBI, beginning immediately after injury, has potential to improve prognostic accuracy and patient care. For instance, identifying poor prognosis as early as possible could be vital for informing prompt personalized treatment to improve outcome by ameliorating physiologic insults in real time as they are developing. In this review, we will discuss molecular markers, imaging techniques, and optical technologies that, when performed within the first $24 \mathrm{~h}$ after return of spontaneous circulation (ROSC), may provide the potential to improve short- term and long-term prognosis and open avenues for novel therapeutic intervention. We will conclude by discussing the current state of treatment, beginning with TTM and expanding to include pharmacological therapies and hemodynamic interventions.

\section{Mechanisms of Brain Injury Following Global Ischemia and Reperfusion}

\section{Causes of CA}

Sudden CA can be dichotomized to shockable and nonshockable presenting rhythms and whether the occurrence is in-hospital or out-of-the-hospital. Etiologies of shockable rhythms (ventricular fibrillation (VF) and pulseless ventricular 


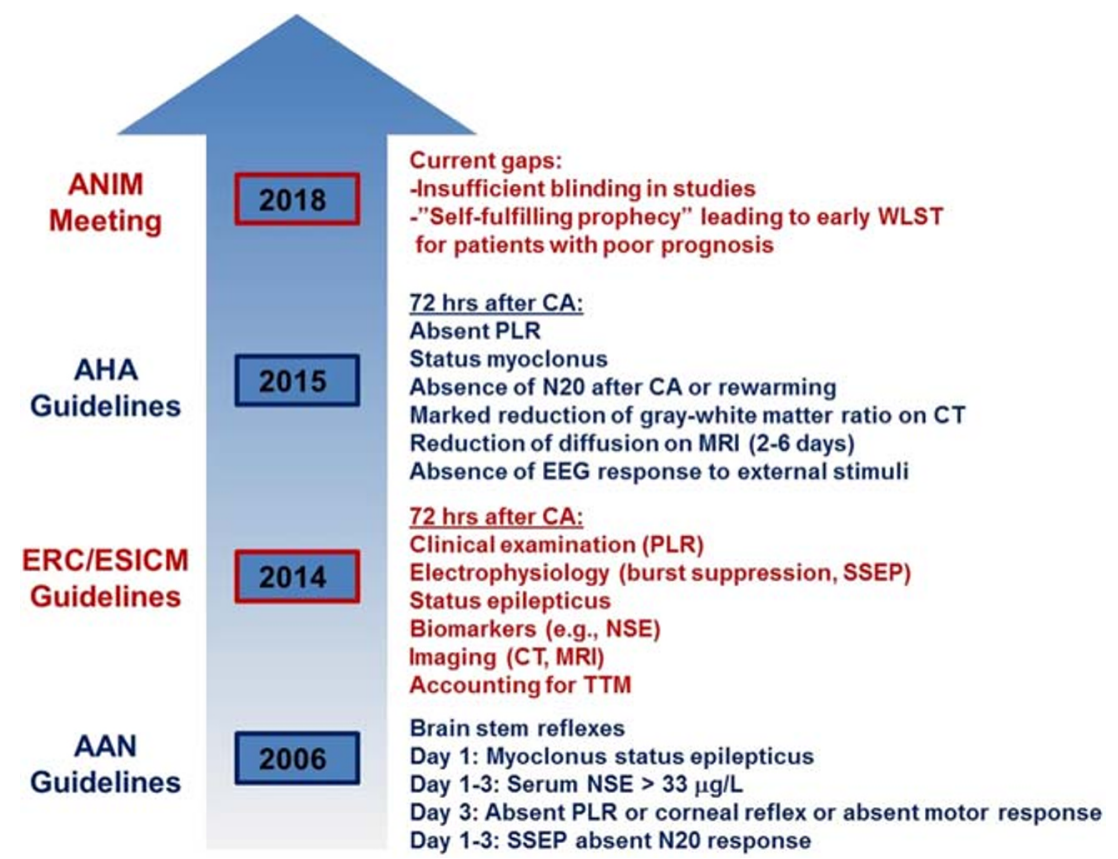

Fig. 1 Recent evolution of guidelines for post-CA patient care. This timeline compares changes in guidelines from three recent meetings (AAN, 2006; ERC/ESICM, 2014; AHA, 2015) emphasizing a multimodal approach to patient care following CA. Also included are gaps in the standard of care for CA patients, as identified during a more recent collaborative meeting (ANIM, 2018). AAN = American Academy of
Neurology; ERC/ESICM = European Resuscitation Council/European Society of Intensive Care Medicine; ANIM = Arbeitstagung NeuroIntensive Medizin; NSE = neuron-specific enolase, $\mathrm{PLR}=$ pupillary light reflex; SSEP $=$ somatosensory evoked potential; MRI $=$ magnetic resonance imaging, $\mathrm{CT}=$ computerized tomography; WLST $=$ withdrawal of life-sustaining therapy tachycardia (VT)) are typically cardiac in origin and consist of dysrhythmic events that cause the heart to suddenly stop. Although shockable rhythms have usually been the predominant cause of CA in adults, their prevalence has recently declined [9, 10]. This trend has been linked to an increase in interventions such as coronary stents, pacemakers, implanted defibrillators, anti-platelet medication, and coronary artery bypass graft (CABG) surgery [9]. Shockable rhythms have been associated with better survival rates than nonshockable rhythms (pulseless electrical activity (PEA) and ventricular asystole) [11-13].

Causes of nonshockable CA typically include respiratory failure (e.g., drowning, drug overdose, choking, suffocation, hanging). Respiratory failure leading to nonshockable CA is characterized by a prolonged prearrest period of hypoxia and hypercapnia contributing to the dysfunction of the cardiopulmonary system. Progression of such rapid, untreated respiratory failure can eventually lead to hypotension, bradycardia, and typically the development of pulseless electrical activity or asystole. Meanwhile, death by hanging can induce a state of respiratory failure by the compression to the airway or fracture to the hyoid bone but typically is a result of interruption of venous and/or arterial cerebral blood flow by different degrees of compression of these vessels [14].

In a canine model, ischemic brain damage was observed to be greater following $7 \mathrm{~min}$ of asphyxial CA than after $10 \mathrm{~min}$ of VF CA [15]. This result suggests that shockable and nonshockable CA involve different mechanisms of brain injury that may require different types of treatment. More recently, a study comparing shockable (VF) with nonshockable (asphyxia) CA in rats $(n=25)$ and humans $(n=1007)$ found that VF CA was associated with less severe brain injury $(p<$ 0.001) and more favorable outcome after ROSC [16]. Among nonshockable rhythms, a Swedish registry of cardiopulmonary resuscitation reported greater survival rates in patients with PEA than those with asystole, suggesting that resuscitative care may benefit from differentiating different types of nonshockable rhythms to better understand and possibly improve neurological outcome in a more patient-specific manner [17].

\section{Hemodynamic Changes}

CA leads to reduced cerebral blood flow (CBF), initiating a cascade of primary metabolic dysfunction in the neurons and secondary reperfusion injuries to the brain (Fig. 2) [18]. Cerebral perfusion after $\mathrm{CA}$ and resuscitation can be characterized by a gradual, multi-phasic (Table 1) restoration of CBF and cerebral autoregulation over the first $72 \mathrm{~h}[19,20]$. The initial post-resuscitation increase in blood pressure and $\mathrm{CBF}$ is termed reactive hyperemia. During this period, the ratio of $\mathrm{CBF}$ to cerebral metabolic rate of oxygen $\left(\mathrm{CMRO}_{2}\right)$ will often exceed its normal range. Post-ischemia/reperfusion rises in 


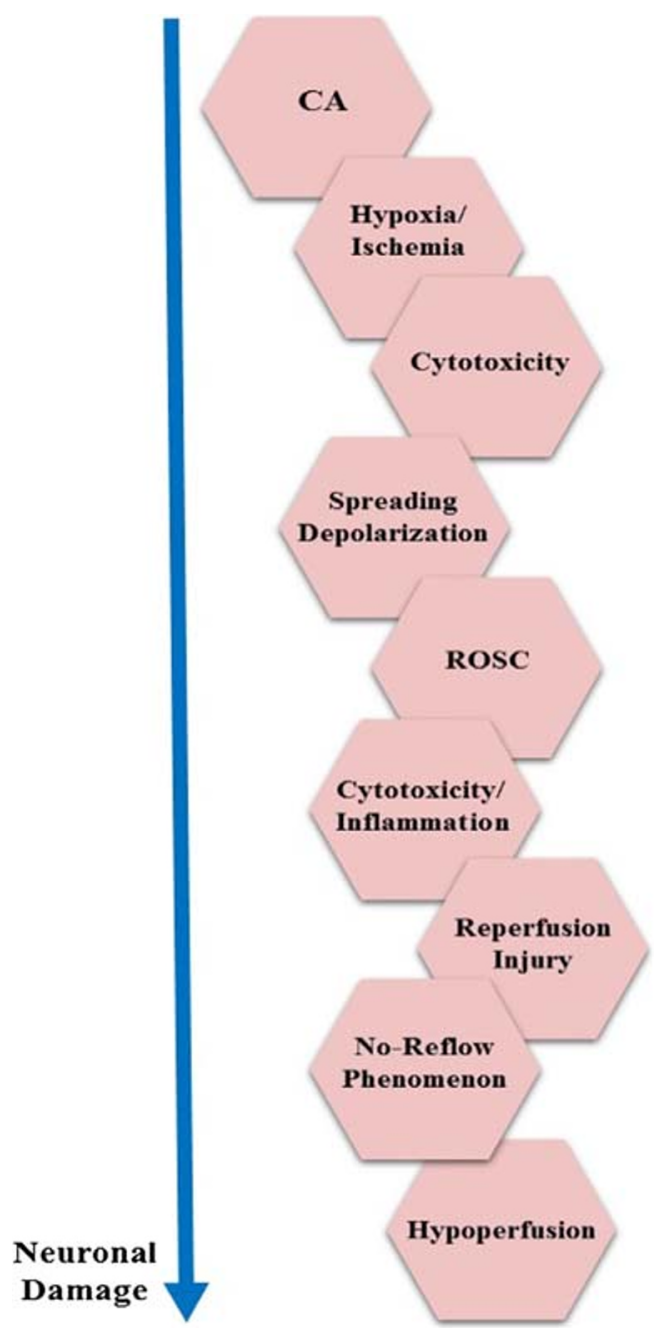

Fig. 2 Mechanisms of post-CA neuronal damage. CA causes hypoxicischemic damage, leading to cytotoxicity and ultimately triggering cellular shutdown and spreading depolarization. Following ROSC, CBF is restored but mismatches between perfusion and metabolism can lead to ischemic injury (no-reflow) or luxury perfusion (reperfusion injury)

$\mathrm{CBF}$ to $\mathrm{CMRO}_{2}$, whether acute or delayed, have been referred to as "luxury perfusion," which has been linked to a loss in vascular tone and vasodilation secondary to acidosis [21-23].

Reactive hyperemia is followed by hypoperfusion, a decrease in CBF that can exacerbate secondary injury. Hypoperfusion can arise as the result of the no-reflow phenomenon (incomplete microvascular filling during reperfusion) [24-26] and the actions of vasoconstrictors such as 20-hydroxyeicosatetraenoic acid (20-HETE) and endothelin-1 [27, 28]. As CBF is restored, the mean flow velocity in the middle cerebral artery $\left(\mathrm{MFV}_{\mathrm{MCA}}\right)$ increases toward normal in CA survivors, while $\mathrm{MFV}_{\mathrm{MCA}}$ is abnormally high in nonsurvivors [29], supporting a link between "luxury perfusion" and poor outcome. If vascular-specific markers can be actively monitored following resuscitation, $\mathrm{CBF}$-targeted interventions may be targeted to ameliorate secondary injury [27].
Table 1 Three hemodynamic stages following resuscitation

\begin{tabular}{|c|c|c|}
\hline $\begin{array}{l}\text { Hyperemia } \\
(0-30 \text { min })\end{array}$ & $\begin{array}{l}\text { Hypoperfusion } \\
(30 \text { min-12 h) }\end{array}$ & $\begin{array}{l}\text { Restoration of blood } \\
\text { flow }(12-72 \mathrm{~h})\end{array}$ \\
\hline $\begin{array}{l}\text { - Hyperemia linked to } \\
\text { cerebral } \\
\text { vasoparalysis [35] } \\
\text { - Vasoparalysis linked to } \\
\text { increasing lactic acid } \\
\text { from anaerobic } \\
\text { respiration [36], } \\
\text { NO [37], and } \\
\text { adenosine [38] } \\
\text { - Loss of vascular tone } \\
\text { is independent of } \\
\text { changes in BP } \\
\text { or reactivity } \\
\text { to } \mathrm{CO}_{2}, \text { which is } \\
\text { preserved [19,21] }\end{array}$ & $\begin{array}{l}\text { - CBF decreases } \\
\text { by } 50 \%[39,40] \\
\text { - Hypoperfusion linked } \\
\text { to intravascular } \\
\text { stasis (no-reflow } \\
\text { phenomenon) [24] } \\
\text { and vasoconstriction } \\
\text { [27] } \\
\text { - Imbalance of } \\
\text { vasodilators (e.g., } \\
\text { NO) [41] and } \\
\text { vasoconstrictors (e.g., } \\
\text { endothelin-1) [28] } \\
\text { contributes to } \\
\text { hypoperfusion }\end{array}$ & $\begin{array}{l}\text { - In survivors, large } \\
\text { vessel blood flow } \\
\text { exhibits gradual } \\
\text { return to } \\
\text { near-baseline, } \\
\text { along with } \\
\text { increased } \\
\text { metabolism [42] } \\
\text { - Increases in large } \\
\text { vessel blood flow } \\
\text { observed in } \\
\text { nonsurvivors [29] }\end{array}$ \\
\hline
\end{tabular}

Following resuscitation, three stages of hemodynamic alteration have been observed in patients and preclinical models. The first stage (hyperemia) is marked by increased blood flow. The second phase (hypoperfusion) is characterized by a reduction in blood flow. The third stage involves the recovery of near-normal CBF. Each box highlights specific pathophysiologic mechanisms linked to these hemodynamic changes

$\mathrm{NO}=$ nitric oxide, $\mathrm{BP}=$ blood pressure, $\mathrm{CBF}=$ cerebral blood flow

CA-induced HIBI is linked to the disruption of normal cerebrovascular autoregulation, which protects the healthy brain from hemodynamic disturbances. Cerebrovascular autoregulation maintains constant $\mathrm{CBF}$ over a range of mean arterial pressure (MAP) (usually $50-150 \mathrm{mmHg}$ ). Brain injury after resuscitation has been linked to a right shift (higher MAP maximum) and narrowing of MAP on the autoregulation curve [30-33]. In pig models, hypothermia after hypoxicasphyxial CA has been associated with a decrease in the right shift and a decrease in CBF [32].

Despite the well-known relationship between MAP and $\mathrm{CBF}$, there is a lack of knowledge about optimal blood pressure targets after resuscitation for CA patients [33, 34].

Current guidelines suggest avoiding hypotension [4, 43, 44]. More recent studies suggest maintaining elevated MAP following $\mathrm{CA}$ to adequately perfuse the brain and maintain optimal CBF in the setting of cerebral dysregulation [44-46]. In one recent study, good neurological outcome (modified Rankin Scale $\leq 3$ ) upon discharge from the hospital was associated with MAP $>90 \mathrm{mmHg}$ in the first $6 \mathrm{~h}$ after resuscitation [44]. A second recent study, focused on CA patients with initial shockable rhythms, suggested that MAP targets should be $>75 \mathrm{mmHg}$ to improve neurological outcome in that patient population [46].

Understanding cerebral autoregulation is critical for informing optimal MAP targets for CA patients. For example, patients with hypertension exhibit a cerebral autoregulation curve that is shifted to the right, suggesting that hypertensive 
patients may particularly benefit from higher blood pressure targets after CA [30]. Recently, methods for more individualized management of post-CA HIBI have been investigated. For instance, jugular bulb microdialysis is currently being used to assess cerebral oxidative metabolism by measuring lactate-to-pyruvate (LP) ratio, in which a high LP ratio is associated with anaerobic metabolism, alongside neurological outcome in a randomized control trial $(n=66)$ comparing low (63 $\mathrm{mmHg}$ ) versus high (77 mmHg) MAP following CA [45].

\section{Metabolic Stress}

Intracellular metabolic and ionic changes are hallmarks of ischemic injury that play an important role in homeostasis and neuronal survival. The cellular mechanisms of post-CA cerebral damage can be divided into two phases: primary and secondary injury.

The primary injury phase of HIBI is characterized by cellular excitotoxicity leading to neuronal and glial cell death. Oxygen is depleted within 15-20 s [6], causing loss of ATP production within $5 \mathrm{~min}$ [47-50], followed by anaerobic glycolysis for 4-5 min [51]. Inactivation of ATP dependent channels leads to cellular swelling (cytotoxic edema), accumulation of lactic acid, and increases in intracellular $\mathrm{Ca}^{2+}$. Increases in calcium also lead to membrane depolarization and release of glutamate largely mediated by NMDA receptors, which further increase the concentration of $\mathrm{Ca}^{2+}$. In vivo studies have shown that the concentration of $\mathrm{Ca}^{2+}$ in the hippocampus is substantially elevated during ischemia, and the reversal of these alterations during reperfusion has different dynamics in area CA3 than area CA1 [52]. Calcium activates apoptotic cascades involving caspases, calpains, proteases, phospholipases, and oxygen free radicals. Despite NMDA's large role in $\mathrm{Ca}^{2+}$ influx and "excitotoxicity", clinical trials using NMDA receptor antagonists were considered unsuccessful $[53,54]$.

Management of HIBI is mainly focused on limiting secondary injury [55]. Secondary injury involves a physiologic response to the imbalance of oxygen demand and supply. Immediately following resuscitation, reperfusion injury causes microvascular dysfunction, hyperoxia, cytotoxicity, inflammatory processes, and cerebral edema. Reperfusion exacerbates cellular excitotoxicity by delivering oxygen as a substrate for reactive oxygen species (ROS) and enzymatic reactions [56]. Endothelial dysfunction from ROS is responsible for impaired vasomotor regulation, decreased endothelial anticoagulation causing microthrombi [57, 58], and impaired blood-brain-barrier (BBB) permeability $[59,60]$. Activation of lytic enzymes disrupts mitochondrial function and further contributes to loss of homeostasis and perpetuates necrosis $[18,56,61]$. Mitochondria are responsible for buffering cytosolic $\mathrm{Ca}^{2+}$ concentrations. Mitochondrial $\mathrm{Ca}^{2+}$ uniporters can be genetically deleted, leading to some neuroprotection during ischemia models, suggesting that they may be potential therapeutic targets in global ischemia [62, 63]. Also, we and others have recently shown that mitochondrial $\mathrm{Zn}^{2+}$ accumulation appears to precede and contribute to this mitochondrial $\mathrm{Ca}^{2+}$ dysregulation that eventually leads to neurotoxicity in selective CA1 pyramidal neurons, highlighting the potential therapeutic benefits of controlling such upstream mitochondrial $\mathrm{Zn}^{2+}$ dysregulation [64, 65]. Ischemic changes and reperfusion injuries are more deleterious to selective regions of the brain like the hippocampus (CA1 in particular), frontoparietal cortex (layers III, V, VI), basal ganglia, and Purkinje cells of the cerebellum [56]. Activation of lytic enzymes, apoptotic signaling cascade, and dysfunctional mitochondria all enhance excitotoxicity and lead to further irreversible brain damage [56].

\section{Inflammation}

The immune response following $\mathrm{CA}$ is orchestrated by a number of different inflammatory cells and markers. The process is complex and discussing it in totality would be beyond the scope of this review. Here, we summarize recent research into the role of microglia and briefly discuss inflammatory processes involving astrocytes and T lymphocytes. The inflammatory response has two major phases: 1) activation of resident macrophages and endothelial cells $[56,66] ; 2)$ influx of peripheral inflammatory cells $[56,67]$.

Microglia, resident macrophages of the central nervous system (CNS), are activated within minutes of insult and will persist for days [68]. Microglia have long been thought to exacerbate ischemic injury, but current research highlights their "biphasic" or "dual" role after cerebral ischemia [60, 69]. Specifically, microglia not only release ROS and produce inflammatory cytokines and proteases $[60,70]$, they also clear necrotic debris and produce anti-inflammatory cytokines and growth factors $[60,71]$. New therapeutic targets aim to control the regulatory mechanisms for microglial activation and polarization [69]. Clinical trials with stem cells and microRNA have shown potential for modulating microglia at different stages of ischemic stroke $[60,69,72]$, and may hold promise for global ischemia.

Microglia, endothelial activation, astrocytes, and matrix metalloproteinases (MMPs) contribute to the breakdown of the BBB. Disruption of the BBB is associated with cerebral vasogenic edema, hemorrhagic transformation, leukocyte infiltration, and leakage of toxins [60]. Temporary BBB disruption during "no-flow" periods has also been observed in rodents via MRI variance imaging, with recovery of BBB $48 \mathrm{~h}$ later $[68,73]$. Interestingly, microglia have also been shown to release progranulin, a growth factor associated with neurovascular protection and attenuation of BBB disruption after ischemic stroke [74-77]. In astrocytes, aquaporin 4 (AQP4) is upregulated after ROSC and associated with early 
vasogenic edema following CA [78]. In rodents, AQP4 inhibitors such as AER-271 mitigate early edema $3 \mathrm{~h}$ after ROSC [79]. Furthermore, loss of ATP results in impaired function of $\mathrm{Na}^{+} / \mathrm{K}^{+}$pumps, leading to neuronal and astrocyte swelling due to loss of the membrane potential. Inability of neurotransmitter reuptake causes an increase in extracellular glutamate, resulting in excitotoxicity. Lactic acid, free radicals, and arachidonic acid build up much like in sepsis.

Cerebral edema is recognized as a robust factor in prognostication for neurological outcome, and one key goal of targeted therapy is to minimize edema following CA [56, 80, 81]. Cellular edema compresses surrounding capillaries, further reducing blood flow, increasing intracranial pressure and increasing $\mathrm{Ca}^{2+}$ influx. Leaks in the BBB result in the elevated influx of T-lymphocytes, particularly cytotoxic $\mathrm{T}$ Cells (CD8+), at $3 \mathrm{~h}$ after ROSC [68]. In fact, a recent preclinical study showed that mice lacking functional T-cells exhibited significantly reduced ischemic damage to neurons in the CA1 region of the hippocampus [82]. Recent preclinical studies have also shown mitigation of post-CA cerebral edema by SUR1-TRPM4 channel inhibitors, such as glibenclamide (glyburide), leading to improved outcome [83, 84], warranting their testing in clinical studies as has been done in large hemispheric stroke.

\section{Temperature}

Figure 3 summarizes key effects of temperature on the brain following CA-induced HIBI. Hyperthermia is associated with worse neurological outcome following HIBI [18, 85, 86]. Preclinical studies have demonstrated an increase in infarction size by $43.4 \%$ (95\% CI, 29.8-56.9\%) as a function of elevated temperature following stroke, and hyperthermia was shown to be even more harmful if present for over $2 \mathrm{~h}$ [87]. Thermotoxicity has been linked to pathophysiological mechanisms that further exacerbate ischemic and reperfusion injuries. For example, increased temperature $\left(38-39^{\circ} \mathrm{C}\right)$ is associated with greater BBB permeability [88], which is associated with cerebral vasogenic edema and altered intracranial pressure (ICP) [18]. Hyperthermia has also been linked to increases in glutamate production, which adds to $\mathrm{Ca}^{2+}$ influx, activation of metabolic pathways, and perpetuation of this vicious cycle ending in neuronal death [89-91]. Hyperthermia may also be associated with impaired autoregulation in CA patients [18]. Additionally, hyperthermia decreases the threshold for seizures $[18,55]$, which are often indicative of poor neurological recovery $[92,93]$. On the other hand, different degrees of hypothermia seem to have little effect on seizures as there were no significant difference in the prevalence of seizures, or the ability of seizures to prognose outcome, in patients whose temperature was lowered to $33{ }^{\circ} \mathrm{C}$ versus $36{ }^{\circ} \mathrm{C}$ [93].

Experimental findings have strongly supported immediate cooling by $3-5^{\circ} \mathrm{C}$ following resuscitation and continuing for approximately $48-72 \mathrm{~h}$ for optimal neuroprotection against secondary injury $[94,95]$. Immediate therapeutic hypothermia in rat models improves cerebral blood flow (CBF) restoration and maintenance following ROSC and results in better neurological outcome [96]. Cerebral cooling following global ischemia was associated with fewer and shorter seizures in piglets [97, 98]. Furthermore, hypothermia has been associated with reductions in cerebral metabolism, excitotoxicity, free radical production, and BBB permeability $[95,99,100]$. In fact, cerebral metabolism is reduced at a rate of $5-7 \%$ for every 1 degree Celsius drop in temperature, emphasizing the impact of even a small change in temperature [95, 99, 101, 102]. In rodent models of cerebral ischemia, hypothermia was linked to reductions in lactate dehydrogenase (LDH) activity [103],
Fig. 3 Effects of temperature on the post-CA brain. Core temperatures of $37.5^{\circ} \mathrm{C}$ and above have been associated with deleterious changes in the brain after CA. However, if core temperature is temporarily reduced, therapeutic effects can be achieved. However, hypothermia also increases risk of complications such as bradycardia and impaired glycemic control. $\mathrm{CBF}=$ cerebral blood flow, $\mathrm{BBB}=$ blood-brain barrier

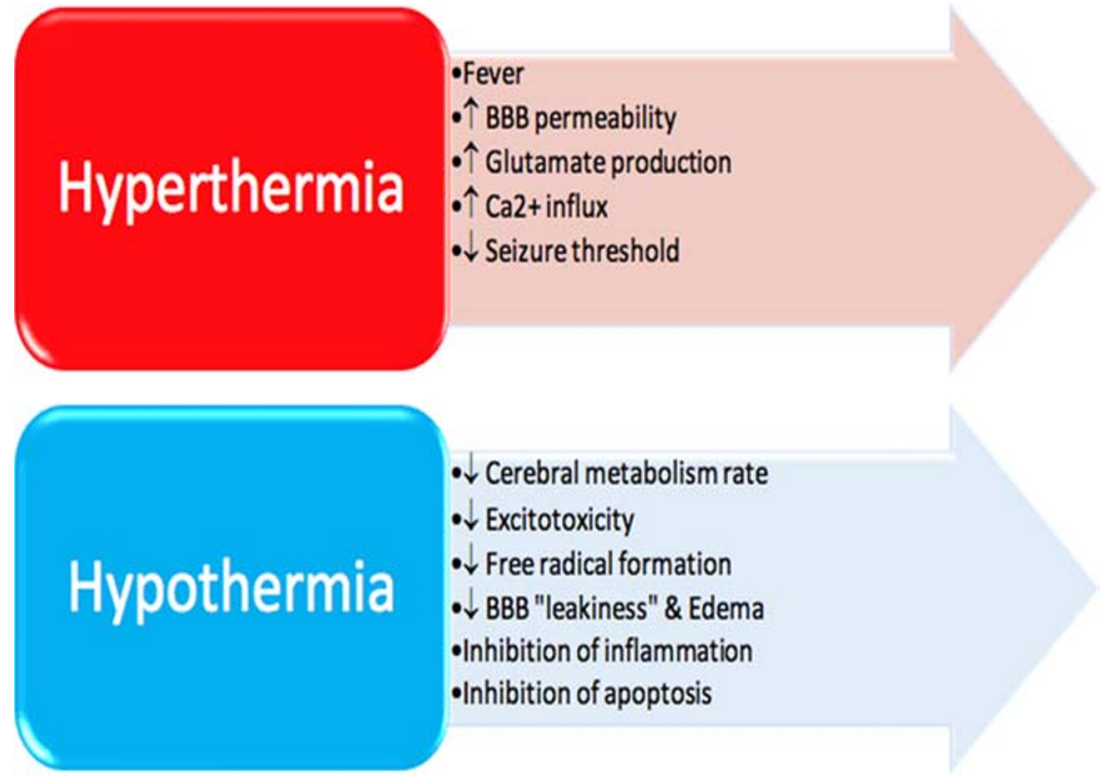


free fatty acid accumulation [104], and excitatory amino acid (EAA) production $[105,106]$. Indeed, for rats maintained at $33{ }^{\circ} \mathrm{C}$ and $30^{\circ} \mathrm{C}$, glutamate release was inhibited completely and dopamine release was reduced [104]. Such reduction of EAA helps to delay onset of, and damage due to, anoxic cell depolarization [107]. Moreover, hypothermia was shown to suppress nitric oxide and superoxide species in hippocampal slice cultures [108] and during ischemia and reperfusion in gerbils [109]. Also, the rapidity of temperature change after CA is important, as shown by one study demonstrating cooling within $1 \mathrm{~h}$ of global ischemia in a rodent model was associated with reduction in BBB leakiness and brain edema $24 \mathrm{~h}$ later [110].

Cooling is also known to be involved with inhibition of neuro-inflammatory and apoptotic pathways [95, 100, 111]. Furthermore, hypothermia has been associated with decreased microglial and nuclear NFkB activation [112]. Numerous studies have demonstrated hypothermic disruption of both the intrinsic and extrinsic pathways of apoptosis [100]. For instance, hypothermia has been linked to activation of antiapoptotic Bcl-2 and suppression of pro-apoptotic factor BAX [113]. Reductions in pro-inflammatory cytokines (IL-1b, IL-6, IL-18, and TNF) [114-116] and increases in antiinflammatory cytokines (IL-10) [117] have both been observed with cooling.

It is important to note that therapeutic hypothermia carries several well documented clinical risks. Hypothermia has been associated with a decrease in cardiac output of about $25-40 \%$ secondary to temperature induced bradycardia $[118,119]$. Hypothermia has also been linked to vasodilation of coronary arteries in healthy adults, as well as vasoconstriction of coronary arteries in adults with severe atherosclerotic disease [120]. Other risks of hypothermia include immunosuppression, risk of infection, electrolyte disturbances, insulin resistance, impaired drug clearance, mild coagulopathy, and cold diuresis [95].

\section{Techniques for Injury Assessment, Monitoring, and Prognosis}

Accurate assessment of HIBI secondary to CA, continuous monitoring of CA-induced cerebral alterations, and improved prognosis of neurological recovery require multimodal approaches. Clinical guidelines for assessment of HIBI patients include testing brainstem reflexes and assessing EEG activity. When possible, it is also recommended to measure somatosensory evoked potential (SSEP), the EEG recorded activity induced by a stimulus (usually electrical activity to the median nerve). Additional modalities include brain imaging (e.g., computed tomography; magnetic resonance imaging; nearinfrared spectroscopy) and biomarker assays (e.g., neuronspecific enolase).
A retrospective cohort study of 226 unconscious postCA patients at a single tertiary care center from 2011-2017 compared the false predictive rate (FPR) of this multimodal approach for three different sets of guidelines. The ERC/ ESICM (2014) guidelines proved more predictive of poor neurological outcome at 6 months $(\mathrm{FPR}<0 \%)$ than the American Academy of Neurology (AAN) guidelines (FPR $<8 \%$ ) or the American Heart Association (AHA) guidelines (FPR $<12 \%)$ [121]. The most robust predictors of poor neurological outcome using the ERC/ESICM guidelines were absence of N20 SSEP and/or absence of pupillary and corneal reflexes [121].

When using a multimodal approach, it is possible to minimize the degree of "self-fulfilling prophecy" and premature withdrawal of life-sustaining therapy (WLST) since prognostic limitations of relying on any one single approach can be mitigated [121-124]. However, some of the aforementioned tools and tests are expensive and require highly-trained personnel to interpret the results $[122,125]$.

\section{Clinical Examination}

Two landmark studies in 1974 [126] and 1977 [127] demonstrated the association between with neurological outcome of comatose CA survivors and parameters measured via initial clinical examination. In 1985, a multicenter study evaluated 210 comatose patients and established the Levy Criteria, the first set of guidelines to predict long-term neurological outcome [128]. Subsequently, these criteria evolved into the currently used Cerebral Performance Categories (CPC) to measure neurological outcome. CPC 1 represents the best possible outcome, with minor cranial nerve abnormalities and other mild neurological and psychological deficits but overall ability to lead a normal life. CPC 5 represents death. Prior to 2006, neurological outcome was dichotomized between "good" (CPC 1-3) and "poor" (CPC 4-5). In 2015, the Utstein Recommendations were to include CPC score of 3 and under as "poor" due to the patient's limited cognition and severe neurological deficits $[129,130]$. Alternative measurements include the Glasgow Outcome Scale (GOS) and modified Rankin Scale (mRS).

An absent pupillary light reflex (PLR) $72 \mathrm{~h}$ after CA has been shown in many studies to be prognostic of poor outcome (CPC score of 3-5 at discharge) [3,128, 131]. Although PLR is often dichotomized as either absent or present, recent studies have used automated pupillometry to quantify the degree of pupillary constriction. In one such study employing pupillometry, 55 adult patients were assessed at the start of TTM, approximately $6 \mathrm{~h}$ after ROSC, and throughout $24 \mathrm{~h}$ of TTM, finding that NPi $<$ 0.37 (Neurological Pupil index). By $6 \mathrm{~h}$ after ROSC, quantitative pupillometry was highly predictive of neurological outcome at discharge [131]. Other aspects of the clinical exam are focused on the brain stem response, including corneal reflex and motor 
response to pain. The main limitation in examining brain reflexes is their limited sensitivity in predicting good recovery as well as suppressive effects of sedation and neuromuscular blocking drugs $[124,132]$. Either completely absent motor response or the presence of extensor (decerebrate) posturing to pain is defined as motor score $(M)=1$ or 2, respectively, on the Glasgow Coma Scale. The ERC-ESICM recommends testing corneal reflex and PLR at $72 \mathrm{~h}$ while cautioning the interpretation of a low motor score of 1 or 2 on the Glasgow Coma Scale due to low specificity [124]. Neverthelesss, motor response has a high sensitivity and is best used in conjunction with other neuroprognosticators. Current research is also investigating the accuracy of optic nerve sheath diameter in determining neurological outcome (NCT03195881).

Patients presenting with myoclonic status epilepticus (MSE) have traditionally been thought to have a poor prognosis; however, exceptions to this have also been reported, especially in the era of TTM [43]. More invasive technologies that include intracranial monitoring have shown to be useful in select patients, but these techniques can carry risks, especially in patients with coagulopathy, and larger studies are needed for further validation [123].

\section{Brain Imaging}

The ratio of gray matter to white matter, measured with computed tomography (CT) within the first $48 \mathrm{~h}$ after resuscitation, has been shown to predict outcome following CA [133-136]. Lower values of the gray/white matter ratio can indicate increased edema, which reduces the ability of the gray matter to attenuate the CT source [136]. Combining CT data measured within 3 days of resuscitation with Glasgow Coma Scale data acquired 3 days after resuscitation showed potential for improving prognostication of recovery 6 months after resuscitation, relative to using only the Glasgow scale [137]. Combining CT data with neuronspecific enolase (NSE) testing (see Section 3.4) was shown to improve prognostication of patient recovery from $\mathrm{CA}$, relative to either method individually [138].

Obtaining quantitative information about changes in gray matter and white matter independently is critical for assessing hypoxic-ischemic brain injury, since gray matter is more vulnerable to hypoxia than white matter [55] and CA-induced changes in gray matter in the cortex are different than those in the subcortex [139]. Recently, advances in MRI data processing for magnetic resonance imaging (MRI) have increased the precision with which hypoxia-related structural alterations in gray matter can be quantified. This has led to the creation of multivariate models combining changes in cortical thickness with alterations in gray matter volume (both measured with conventional T1-weighted MRI) to predict brain recovery 1 year after CA in patients [139]. Diffusion-weighted MRI has shown high sensitivity for predicting post-CA recovery, but it can suffer from poor specificity because patients who are younger, healthier, or underwent less-severe injury can often have good long-term prognosis despite initially showing abnormalities on MRI [140-142].

Recently, techniques such as diffusion-weighting [143], phase analysis [144], and connectivity mapping [145] have been used to obtain additional quantitative information from MRI to better characterize ischemic damage in the brain. MRI data has also been used in tandem with $\mathrm{CT}$ data to improve prediction of neurological recovery, showing that the combination of these two modalities provided better prognostic accuracy than either of the two individually[146]. Furthermore, positron emission tomography (PET) has been used to measure $\mathrm{CBF}$ and brain oxygen metabolism in a preclinical CA model, revealing oligemia and reduced oxygen extraction in the cortex concomitant with excess CBF relative to oxygen extraction in the cerebellum [147].

\section{Electrophysiological Tools: EEG, SSEP, and BIS}

Electroencephalography (EEG) is a technique that measures the changes in electrical potential from brain activity. Different EEG waveforms are observed in healthy brains versus disease states such as coma, seizure, or dementia. After HIBI, various EEG patterns have been identified as being benign or malignant. Benign EEG activity includes theta dominant or frontal rhythmic delta, whereas malignant activity includes isoelectric (silent), low amplitude delta, alpha coma or burst suppression [148]. Malignant EEG patterns have demonstrated low sensitivity but high specificity for identifying poor outcome [149]. This result may seem counterintuitive, but the presence of benign EEG is encountered more commonly than expected in post-CA patients, yielding low specificity.

Another method for prognostication is to apply electrical current to peripheral nerves to induce EEG patterns, commonly referred to as somatosensory evoked potentials (SSEP). For example, the absence of the N20 cortical wave during median nerve stimulation has provided $100 \%$ specificity for identifying poor outcomes in multiple studies [3]. The explanation for these findings was that cortical tissue is much more prone to anoxic brain injury, so by the time brainstem reflexes are absent, the cortex is irreversibly damaged. A prospective study [150] examined whether using combinations of 2 or more variables (e.g., bilaterally absent SSEP, unreactive EEG background, early myoclonus, incomplete recovery of brainstem reflexes) predicted survivability following anoxic brain injury. When 2 or more of the aforementioned variables were used, a specificity of 1 , sensitivity of 0.72 and an unweighted accuracy of 0.9 were reported. However, a limitation in this study was that during post-CA care, administration of antiepileptics or sedatives could cause exogenous changes to EEGs. Despite the high specificity of SSEPs in identifying poor outcome, it 
can often be difficult to obtain them in a timely manner in the intensive care unit setting due to the need for someone experienced in the technique.

The bispectral index (BIS), a quantity obtained from EEG that has historically been used to characterize depth of anesthesia, is another potential prognostication method for assessing neurologic function in CA patients during TTM [151]. In an initial exploratory study, it was discovered that low BIS scores during therapeutic hypothermia in CA patients predicted poor neurologic outcome after discharge, and that decrease in BIS was associated with an increase in the odds of poor outcome [151]. In a subsequent study measuring CA patients undergoing TTM, the "good outcome" (cerebral performance category score of 1-2) patient group had a significantly higher mean BIS value after ROSC compared to the "poor outcome" (cerebral performance category score of 3-5) patient group [152]. Although these studies show promising uses for BIS, which is far easier to implement in the intensive care setting compared to SSEPs, several limitations exist with the usage of BIS. For instance, since BIS only outputs a processed EEG signal, BIS signal interference from confounding factors such as extraneous EMG activity or electrical devices such as pacemakers cannot easily be detected [153]. More studies concomitantly measuring BIS and EEG signals are needed to confirm the accuracy of BIS prediction of poor neurologic outcome. Nevertheless, EEG-based prognostication techniques show significant promise for predicting poor post-CA outcomes and thus can be of great use to inform decisions about withdrawal of care. However, there remains an unmet need for a reliable positive prognosticator to aid clinical decisions beyond withdrawal of care.

\section{Molecular Biomarkers}

Neuron-specific enolase (NSE) and S100B are neuro-injury biomarkers that may be used as strong early prognostic indicators of poor neurological outcome [154]. Unlike many neuro-prognostic markers, these markers are not significantly influenced by sedatives, neuromuscular relaxants $[155,156]$, temperature changes $\left(33 v s 36^{\circ} \mathrm{C}\right)$, or prolonged hypothermia during standard TTM management [157]. While traditionally, NSE values above $33 \mu \mathrm{g} / \mathrm{L}$ at $48 \mathrm{~h}$ were considered highly prognostic of death or poor neurological outcome, in the more recent TTM era, recent studies suggest that a higher cutoff may be needed to maintain a low false positive rate and that serial measurements may provide added benefit [155]. Another recent study on TTM patients further supported stronger prognostication of NSE values at $48 \mathrm{~h}$ as compared to $24 \mathrm{~h}$, whereas minimal difference was found between values drawn at 48 versus $72 \mathrm{~h}[158]$. NSE is a more robust prognosticator than S100B for poor outcome (CPC 3-5) at 6 months $[155,156]$. However, studies have also shown that combined S100B and procalcitonin measurements at $24 \mathrm{~h}$ after CA are good neuro-prognosticators of poor neurological outcome (CPC 3-5). Combining S100B and procalcitonin biomarkers improved sensitivity from $83.3 \%$ and $70.2 \%$ (measuring S100B and procalcitonin alone, respectively) to $85.1 \%$ [159]. Currently, in the TTM era, there is no clear consensus for the optimal threshold that should be placed on NSE value for best prognostication [132, 154, 155]. However, numerous studies and recent expert recommendations support the use of NSE within a multimodal approach in combination with clinical, imaging, and electrophysiological data, rather than in isolation, to maximize sensitivity and specificity of prognostication [43, 155, 158, 160]. More recent studies have also analyzed miRNA, which are smaller molecules that can cross the blood-brain barrier and may be detectable earlier than NSE [161].

\section{Emerging Tools: Diffuse Optical Spectroscopy and Imaging and Spreading Depolarization}

Over the past two decades, techniques involving diffusely scattered light have become increasingly investigated for characterizing the complex changes in brain tissue resulting from global cerebral ischemia. These methods, collectively known as diffuse optical spectroscopy and Imaging (DOS(I)), and including Near-Infrared Spectroscopy (NIRS), shine visibleto-near-infrared (VIS-NIR) light onto the tissue and use a fiber-optic probe or camera to detect the light that is scattered back to the surface by the tissue [162]. Some of the light is absorbed by tissue constituents such as oxygenated hemoglobin, deoxygenated hemoglobin, water, and lipid, causing wavelength-dependent attenuation in the detected signal. Therefore, by performing DOS(I) at multiple wavelengths, the absorption coefficient (and thus, the concentration) of each individual chromophore in the tissue can be measured.

Early uses of DOS(I) techniques to characterize cerebral ischemia included imaging hemoglobin oxygenation changes in a neonatal piglet hemorrhage model [163] and identifying secondary energy failure via NIRS measurements of Cytochrome aa3 [164]. More recently, NIRS oximetry devices have become more widely incorporated into studies trying to improve prognostication following CA [165-169]. Some applications of these devices include examining the effect of TTM in preclinical models, [170, 171], using NIRS to inform CPR quality and detect ROSC [172], and testing the potential of NIRS for initial "prehospital" assessment of traumatic brain injury severity [173]. However, it is important to note that tissue oxygenation values measured with commercial NIRS systems may not strictly represent cerebral oxygen consumption [174], as perturbations to CBF and oxygen extraction will both impact the measured tissue oxygenation values. Therefore, it is necessary to incorporate multi-modal approaches for more accurate quantitative monitoring of tissue perfusion, oxygenation, and metabolism. 
Over the past decade, numerous hybrid technologies, incorporating multiple modalities of diffuse light, have been investigated for assessing the complex dynamic relationship between cerebral blood flow changes, alterations in brain oxygenation, and deficits in tissue metabolism in response to global cerebral ischemia. Typically, one of the technologies in such a hybrid setup quantifies cerebral blood flow, and the other measures parameters related to brain oxygenation. Using these measurements in tandem provides metrics for characterizing changes in flow-metabolism coupling and cerebral autoregulation. For example, NIRS has been combined with diffuse correlation spectroscopy (DCS) in the neonate brain for quantifying perfusion and metabolism changes associated with hypothermic interventions during cardiopulmonary bypass and encephalopathy $[175,176]$. Furthermore, a hybrid NIRS/laser Doppler approach has been used to quantify limits of autoregulation in a preclinical model of $\mathrm{CA}+\mathrm{CPR}$ with TTM [32]. Also, a combination of laser Doppler and jugular catheter oxygen measurement has been performed to assess the relationship between $\mathrm{CBF}$ and cerebral oxygen extraction in the first $72 \mathrm{~h}$ after resuscitation [20]. Utilizing a multimodal approach, NIRS along with mean arterial pressure (MAP) have been used simultaneously for assessing differences between cerebral and peripheral perfusion to characterize autoregulation [177]. Our group has also examined differences between cerebral perfusion and peripheral perfusion in a preclinical CA model using multiple optical modalities and have found a dissociation between the cerebral and peripheral pulsatility [178]. Moreover, DCS has been used along with oximetry to monitor the potential for preconditioning due to repeated occlusion and reperfusion [179]. Camera-based diffuse optical techniques have also been used for measuring CBF and intrinsic optical signal (IOS; a parameter related to tissue absorption and scattering) along with a voltagesensitive dye to quantify neurovascular coupling in a preclinical CA model $[180,181]$. Recently, in neonates that experienced hypoxic-ischemic encephalopathy shortly after birth, wavelet techniques were employed using NIRS data in combination with blood pressure to quantify autoregulation and using NIRS in tandem with EEG to assess neurovascular coupling [182].

In the future, it may be possible to enhance contrast in diffuse optical hemodynamic measurements by incorporating techniques such as photoacoustic tomography [183] and improve localized detection of cerebral hemodynamic changes using diffuse optical tomography [184] or "whole-head" NIRS with multiple source-detector separations and principal component analysis to separate contributions from different regions of the brain [185]. Additionally, characterizing the biophysical meaning of the tissue scattering changes during cerebral ischemia and reperfusion shows significant potential as a new marker of cytotoxic edema, metabolic compromise, and neuronal injury [186-188]. In fact, our group has recently found in a preclinical model that changes in CBF, tissue oxygenation, cerebral metabolism, and tissue scattering precede, and may be predictive of, EEG recovery in the ultra-early period (first 1-5 min) after reperfusion [187, 189]. Furthermore, we show that the flow-metabolism ratio $\left(\mathrm{CBF} / \mathrm{CMRO}_{2}\right)$ in the brain at ultra-early time points (12 min after ROSC) may be diagnostic of CA severity (duration) and predict bursting, and this metric appears robust across different ischemia durations [190]. Additionally, we recently demonstrated that combining $\mathrm{CBF}$ and tissue oxygenation data shows promise for continuously measuring $\mathrm{CMRO}_{2}$ on an absolute scale (e.g., $\mu \mathrm{M} \mathrm{O} / \mathrm{min}$ ), which has traditionally been more challenging to measure but potentially very important [191]. Absolute $\mathrm{CMRO}_{2}$ measurement enables direct quantitative comparison between cerebral metabolism of multiple subjects or a single subject on multiple days, without the need for baseline measurements or perturbations such as hypercapnia.

One area of rapidly growing interest for both prognostication and potential targeted intervention is the spreading depolarization (SD) theory of neuronal injury from various insults including global ischemia. SD occurs when an insult (e.g., anoxia) causes neurons to depolarize in a wave that propagates and is followed by severe suppression of neuronal electrical activity [192-194]. The extremely energy-demanding strain placed on individual cells during this phenomenon induces physical changes (cell swelling, beading, energy store depletions, and loss of local blood flow) to brain tissue that accompany the electrical alterations. The area surrounding the brain necrosis, known as the penumbra, experiences the SD in waves emanating from the core [195]. Spreading depolarizations occur in conjunction with cytotoxic edema [196, 197]. SD has recently become the topic of intense preclinical and clinical research due to its interest as a potential target for therapeutic intervention [197-200]. Our group has recently shown that analysis of SD and repolarization during CA may play a potential role in very early prognostication of neurological outcome [188].

\section{Targeted Temperature Management}

In 2002, significant improvement in post-CA survival and neurologic function after shockable rhythm was reported in patients treated with induced hypothermia from 32 to $34^{\circ} \mathrm{C}$, a method that became widely adopted in hospitals [201-203]. However, there has been disagreement about the underlying therapeutic mechanisms associated with this temperature range. For example, there has been debate over whether the improved clinical outcomes were associated with the temperature being dropped to $32-34{ }^{\circ} \mathrm{C}$ or whether the effect was simply due to the prevention of fever, since fever has been associated with poorer post-CA outcomes [204-206]. In 
2013, a landmark trial researched the differences in all-cause mortality and neurologic function between patients randomly assigned to TTM at $33{ }^{\circ} \mathrm{C}$ versus $36{ }^{\circ} \mathrm{C}$, showing that hypothermia at $33{ }^{\circ} \mathrm{C}$ did not demonstrate a benefit compared to $36{ }^{\circ} \mathrm{C}$ [207]. The primary outcome, all-cause mortality at the end of this TTM trial, did not differ significantly between the two temperature groups, and the secondary outcomes, poor neurologic function or death at 180 days, also did not show a significant difference.

Further sub-studies stemming from this TTM trial have compared the $33^{\circ} \mathrm{C}$ and $36^{\circ} \mathrm{C}$ treatment groups within different subpopulations, including patients with nonshockable rhythm (NSR). Current guidelines recommend hypothermia for all resuscitated patients regardless of initial rhythm, but evidence for TTM in patients with NSR is limited, and management remains controversial [94, 208, 209]. In 2019, another landmark multicenter study was reported showing that TTM targeting $33{ }^{\circ} \mathrm{C}$ after nonshockable rhythm leads to improved neurological outcome in survivors by 90 days after CA [210]. Prior to this, a recent retrospective cohort study had linked TTM $\left(32-34{ }^{\circ} \mathrm{C}\right.$ within 6 h of ROSC $)$ to decreased mortality and improved neurological outcomes in patients with NSR [209]. Moreover, another recent study found that there was no difference between patient outcomes for TTM at $33{ }^{\circ} \mathrm{C}$ versus $\mathrm{TTM}$ at $36{ }^{\circ} \mathrm{C}$ for NSR patients [211]. Thus, evidence for TTM's benefit in nonshockable rhythm has been significantly strengthened in recent years.

The effects of bradycardia on mortality and neurologic outcome in CA patients were also studied in the patients from the 2013 TTM trial [212]. A subset analysis of the $33{ }^{\circ} \mathrm{C}$ group showed that bradycardia less than 50 beats/ min was independently associated with lower 180-day mortality and lower odds of unfavorable neurologic outcome, and that the $33{ }^{\circ} \mathrm{C}$ group of patients experienced a more pronounced heart rate-lowering effect from the TTM as compared to the $36{ }^{\circ} \mathrm{C}$ group. This effect corroborated the previously known trend that core temperatures lower than $35.5{ }^{\circ} \mathrm{C}$ may lead to the development of sinus bradycardia [95]. However, these independent associations do not definitively prove that TTM at $33{ }^{\circ} \mathrm{C}$ can decrease mortality and improve neurologic outcome as compared to at $36{ }^{\circ} \mathrm{C}$. Two possible confounding factors, including sedation and differences in medication use, were not controlled for in this study. Therefore, further investigation is needed to research the interactions between sedation, medication regimens, and heart rate in CA patients treated with TTM.

The optimal duration of cooling and rewarming is also a controversial topic in TTM. A recent randomized clinical trial compared $24 \mathrm{~h}$ versus $48 \mathrm{~h}$ of $33{ }^{\circ} \mathrm{C}$ TTM in CA patients suffering from shockable versus nonshockable rhythms. Better neurological outcome (CPC 1-2) was observed in the 48-h group than in the 24-h group. However, study results were not statistically significant, requiring larger randomized trials [213]. Furthermore, adverse events were also more common in the 48-h group [214]. Following TTM, slow rewarming is recommended $[43,94,215]$ to avoid the risk of rebound fever over the initial $24 \mathrm{~h}$ following rewarming [216]. However, a recent retrospective observational study compared rewarming at $0.15^{\circ} \mathrm{C} / \mathrm{h}$ versus $0.25{ }^{\circ} \mathrm{C} / \mathrm{h}$ and did not find significant differences in neurological outcome [215]. A current clinical trial (NCT02555254) is further investigating optimal rates of rewarming.

Current standards and guidelines for TTM do not recommend a particular method for modifying core temperature, and research comparing different TTM methods is limited $[217,218]$. One recent retrospective study found endovascular cooling to be more precise than surface cooling, but the neurological outcomes in the two groups were similar [218], while endovascular cooling also requires placing central venous catheters and thus carries its associated risks [94]. Recently, esophageal cooling catheters have been safely implemented during TTM and are increasingly being used [219]. More innovative methods of targeted temperature management are currently being tested. For instance, the PRINCESS Clinical Trial $(n=677)$ randomized patients to either trans-nasal evaporative intra-arrest cooling or to standard of care. Both groups received systemic therapeutic hypothermia $\left(32{ }^{\circ} \mathrm{C}\right.$ or $34{ }^{\circ} \mathrm{C}$ ) for $24 \mathrm{~h}$. The results showed that trans-nasal cooling did not significantly improve 90-day neurological outcome [220]. Furthermore, patients receiving TTM must be carefully monitored to minimize complications related to ventilation, oxygenation, carbon dioxide, bradycardia, hypotension, insulin resistance, infection, fever, acute respiratory disease, shivering, and oversedation [94].

In a study focusing on quality of life and cognitive function after CA, patients from the 2013 TTM trial were invited to complete a follow-up assessment 6 months after discharge from the hospital [221]. Quality of life and cognitive function were assessed via four outcome measures: clinician-reported, performance, observer-reported, and patient-reported. No significant difference was found between the $33{ }^{\circ} \mathrm{C}$ and $36{ }^{\circ} \mathrm{C}$ groups on MMSE, IQCODE, Two Simple Questions, MCS, and PCS scores (all tests for cognitive function, level of daily function and mental recovery, and overall measures of health). The finding that cognitive function did not differ between the two TTM groups was confirmed by a second study [222]. Current research is ongoing to further investigate TTM mechanisms and their effects on quality of life, mortality, and neurological function. For instance, the TTM2 trial is an international multicenter randomized superiority trial, comparing $33{ }^{\circ} \mathrm{C}$ after $\mathrm{CA}$ to early treatment of temperatures greater than $37.8^{\circ} \mathrm{C}$ (NCT02908308). 


\section{Emerging Treatments}

\section{Pharmacotherapy}

Pharmacotherapies in cerebral ischemia continue to be explored and the current research has grown extensively. Here, we will introduce several pharmacotherapies and their accompanying pathways, including SUR1/glyburide, orexin, eicosanoids, prolyl hydroxylase, and ROS inhibitors.

SUR1 is a subunit that regulates intracellular $\mathrm{Ca}^{2+}$-activated nonselective cation channels that are opened by ATP depletion [223]. Typically, SUR1-regulated ion channels are not constitutively expressed in the CNS and are only activated during nerve damage caused by events such as ischemia, trauma, and hemorrhage. Sustained channel opening leads to sodium rushing into the cell, causing water to follow in, precipitating cell swelling and cell death. Glyburide, which has historically been used to treat diabetes mellitus type 2 , is currently undergoing clinical trials (NCT02864953) to treat stroke patients by its mechanism of targeting the SUR1-TRPM4 channel complex and inhibiting its overactivity, thus decreasing edema formation [224, 225]. Indeed, glyburide has been shown to reduce post-CA cerebral edema and improve outcome in animal models [83, 84], suggesting its possible benefit in humans also. The completion of ongoing clinical trials is warranted to investigate this exciting possibility.

Orexin, a hypothalamic excitatory neuropeptide responsible for arousal, also plays an important role in neurological recovery after CA $[226,227]$. Using a rodent model, our group has demonstrated a decline in orexin- $4 \mathrm{~h}$ after resuscitation with a gradual increase to normal levels that temporally coincides with arousal [226]. An intranasal orexin-A treatment administered to rats 30-min after resuscitation was linked to significant reductions in neuroinflammatory markers (IL1b, iNOS, TNF-a, GFAP, CD11b) and accelerated neurological recovery [227]. In further support of a likely important role for orexin in post-CA recovery, our group showed that inhibition of orexin in rats after resuscitation is linked to worse neurological outcome, underscoring a causal relationship between orexinergic activity and arousal level after CA [226].

Eicosanoids, metabolites of arachidonic acid, are produced by cytochrome P450 (CYP) and play a role in vasodilation and vasoconstriction. 20-hydroxyeicosatetraenoic acid (20HETE), an eicosanoid producing CYP enzyme, is an important vasoconstrictor. Inhibition of 20-HETE in a preclinical CA model was associated with improved cortical perfusion and better short-term outcomes [228].

Prolyl hydroxylase domain proteins (PHDs) hydroxylate targets such as hypoxia-inducible transcription factors (HIF). These proteins are upregulated in the presence of oxygen, marking HIF for proteasome degradation. In a murine model, HD1 inhibition was protective against cerebral ischemia [229].
Animal models have played a vital role in improving our understanding of the pathophysiology, prognosis, and potential treatments for HIBI after CA. A recent groundbreaking swine experiment [230] has questioned our understanding of death [231]. Irreversible cellular injury is the ultimate endpoint of HIBI and brain death. Interestingly, Vrsejla et al. have demonstrated a pig brain's ability to resume microcirculation and molecular and cellular activity up to $4 \mathrm{~h}$ postmortem (after decapitation) and to maintain such activity up to $10 \mathrm{~h}$ postmortem during their tests. The cocktail of pharmacologic agents used in their perfusate that was injected in the pig brains to restore brain activity could potentially be key components that provide neuroprotective benefits following CA. These animal experiments have major implications for humans, both in advancement of treatments and prognostication as well as the fundamental definitions we carry for death.

More clinical trials are needed to test proven preclinical pharmacotherapies in humans. Indeed, ongoing clinical trials are investigating gas therapy, including Xenon versus oxygen (NCT0317618), as well as repurposing of compounds such as vitamin C (NCT03509662) following CA. In short, the future of treatment for the globally ischemic brain holds promise as more pharmacologic approaches are tested in the clinical setting.

\section{ROS Inhibitors}

Reactive oxygen species (ROS), the byproducts of metabolic enzymatic reactions, are involved in apoptosis, cell signaling, the immune response, and protein expression $[232,233]$. Under normal conditions, the ROS produced in the brain are cleared by antioxidative enzymes to prevent an overproliferation of ROS. However, during ischemic conditions, antioxidative enzymes are unable to clear the ROS as fast as they are produced, due to increased mitochondrial metabolism of succinate and increased activity of NADH oxidase and xanthine oxidase, among other enzymes. This overproduction of ROS can lead to brain tissue damage, protein degradation or aggregation, lipid peroxidation, DNA damage, and inactivation of key metabolic enzymes.

Therefore, therapies either targeting the generation of ROS or mitigating the effects of formed ROS have been developed to combat excessive ROS proliferation after ischemia. Treatments preventing the formation of ROS include mitochondrial electron transport chain uncouplers, NADPH oxidase inhibitors, and xanthine oxidase inhibitors, whereas treatments mitigating the effects of formed ROS involve ROS scavengers and ROS degradation. Vitamins A, C, and E and lipoic acid are antioxidants used as ROS scavengers, but clinical trials have shown no definitive benefit of using vitamins or supplements to treat ischemic stroke [232, 234, 235]. Use of other free radical scavengers such as NXY-059 and citicoline have not shown demonstrative benefit for patients 
[232, 236, 237]. These findings of ROS scavengers may be attributable to the fact that blanket scavenging may disrupt the physiological effects of ROS, causing a host of other issues [233]. Therefore, more focused scavenging may prove effective at limiting the damage from ROS. Preliminary studies have shown that the other side of the equation, preventing excessive ROS production, may prove beneficial [233, 238], but more studies are needed to confirm the efficacy of inhibiting the generation of ROS.

\section{Perfusion and Oxygenation Targets}

Over the past 10-15 years, a number of studies [7, 34, 44, 239-243] have investigated the ideal targets for blood pressure, $\mathrm{CBF}$, and brain oxygenation during and immediately after CPR. Hyperoxia has long been the standard of care during resuscitation from $\mathrm{CA}$, but this practice is currently a topic of significant debate, as the clinical literature is not consistent on whether hyperoxia or normoxia is better for improving neurological recovery following CA [241]. In a recent cohort study [34], a link was shown between hyperoxia in the first $6 \mathrm{~h}$ after resuscitation and impaired neurological recovery upon discharge from the hospital. Additionally, multiple preclinical studies going back several decades [239, 244, 245] have suggested that normoxia may facilitate better neurological recovery than hyperoxia. However, to properly interpret the effect of inspired oxygen on neurological recovery, it is critical to also understand the relationship between brain oxygenation and other crucial hemodynamic parameters such as MAP and $\mathrm{CO}_{2}$, as was done in a recently completed randomized control trial [242, 246]. This study, known as the COMACARE trial, showed that although elevated target values of oxygen and $\mathrm{CO}_{2}$ produced an increase in brain oxygenation (as measured by NIRS), these interventions did not ultimately lead to a significant change in neuron-specific enolase (NSE) concentration measured $48 \mathrm{~h}$ after resuscitation. Therefore, the optimization of target oxygen level during and immediately after ROSC continues to be an area of active, crucial research. Recently, our group has demonstrated in a preclinical model that it may be critical to target not just oxygenation, but the ratio of cerebral perfusion to oxygen metabolism ( $\mathrm{CBF} / \mathrm{CMRO} 2)$, and that the window for optimizing this value may be quite transient (e.g., within the first several min after ROSC) [190]. We anticipate that future work in this area will continue to emphasize multimodal monitoring and multivariate optimization of cerebral hemodynamic parameters to facilitate improved outcome following CA and CPR.

Recently, several groups (including our own) have investigated the impact of peripheral blood pressure, perfusion, and pulsatility on neurological recovery following global cerebral ischemia. In the cohort study described in [34], it was also found that raising blood pressure within the first $6 \mathrm{~h}$ after ROSC may help improve neurological outcome after CA
[44]. However, it has also been shown that the optimal levels of perfusion to target can vary from patient-to-patient, because these values are dependent on the MAP-CBF autoregulation curve, which can differ among patients [243]. This result emphasizes the need for a personalized-medicine approach to treatment, guided by continuous multimodal monitoring of cerebral autoregulation. New techniques, such as stimulating the vagus nerve [247] may be possible to employ in this context to optimize perfusion as needed for individual patients. Furthermore, targeting specific values of perfusion pressure [248] or even inducing variations in blood pressure [7] may help to facilitate improved neurological recovery. Additionally, our group has shown that in a preclinical model of asphyxial CA and resuscitation, increased peripheral blood pressure pulsatility (e.g., pulse pressure) after resuscitation is associated with worse short-term neurological recovery [178]. This finding, in conjunction with other studies, suggests that monitoring and targeting specific mean arterial pressure as well as the pulse pressure in the periphery and the brain may play an important role in post-resuscitation neurological recovery in patients.

\section{Preconditioning and Postconditioning}

Preconditioning and postconditioning are defined as exposing an organ to sub-lethal injuries before, during, or after a hypoxic insult to build tolerance and mitigate damage. Ischemic tolerance from these procedures has been thoroughly described in other organs such as the heart and kidneys. TTM can be thought of as preconditioning and postconditioning for the brain. This section does not aim to provide a comprehensive review but rather to make the reader aware of the breadth of work in this area and where temperature control may fit into the picture.

Neuroprotective potential is dependent on the type, severity, and duration of the insult. A stimulus that is too great will permanently damage brain tissue, while a stimulus that is too small will result in no neuroprotective effect. This invokes a continuum of the same insult at different intensities: no effect, protective, apoptogenic, and neurogenic. Preconditioning stimuli that are neuroprotective for global ischemia can be produced via a variety of insults. These sublethal conditions include, for example, hypoxia, ischemia, NMDA agonists, ethanol, thrombin, LPS, hyperbaric oxygen, anesthetics, and opioid receptor antagonists. Also, insults can be either global or regional/remote (i.e. induction of a milder ischemia to a peripheral limb) and still provide neuroprotection [249, 250]. All of these mechanisms utilize a few common pathways described below. All of their effects repeatedly have been shown to reduce (at different timepoints and effect) the loss of neurons during an ischemic event. Clinical trials for preconditioning in CA have been initiated to evaluate therapeutic benefit in humans (NCT03093948). 


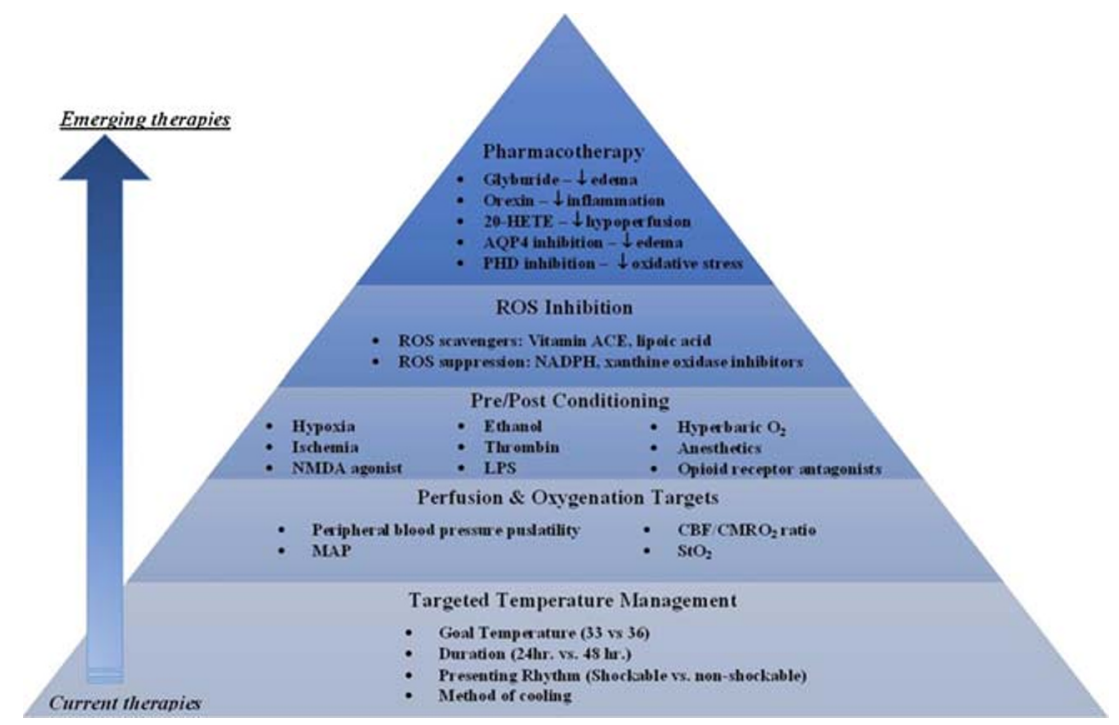

Fig. 4 Targeted therapies for post-CA patient care. The base of the pyramid highlights the currently used treatment for CA patients (TTM), with bullet points identifying TTM parameters that remain topics of debate, interest, or investigation. Upon this foundation, new treatment mechanisms (upper levels of the pyramid) are being introduced. 20-HETE = 20-hydroxyeicosatetraenoic acid; AQP4 = aquaporin 4; ROS = reactive oxygen species; NMDA = LPS $=$ lipopolysaccharide; $\mathrm{MAP}=$ mean arterial pressure; $\mathrm{CBF}=$ cerebral blood flow; $\mathrm{CMRO} 2=$ cerebral metabolic rate of oxygen; $\mathrm{StO} 2=$ tissue oxygenation

suffer from this limitation. Ischemic postconditioning also entails inducing sublethal injuries to the brain parenchyma, but it takes place after the initial insult. Ischemic postconditioning can also be categorized as either classic or remote, where classic is intermittent occlusion of the same vessels that caused the injury and remote is intermittent occlusion of vessels on an extremity. The underlying molecular mechanisms for postconditioning appear to have some similarities to those for preconditioning. One preclinical study showed the possible utility of intermittent ischemic postconditioning in reduction of infarct size [256]. The group performed three cycles of 30-s occlusion/10-s release of the bilateral CCA after reperfusion in rats, robustly reducing infarct size in focal ischemia. In 2009, this group used the same focal ischemic model, but rather than classic postconditioning, they used remote (on a limb) postconditioning to show a similar effect [257] via many of the same pathways described above. Recently, a clinical study showed a decrease in stroke incidence in intracerebral artery stenosis patients using remote ischemic preconditioning by inflating a pneumatic cuff around patients' arms [258]. In this study, the incidence of recurrent stroke at 300 days was $26.7 \%$ in the control while the preconditioned group demonstrated a reduction in the incidence of recurrent stroke to $7.9 \%$ at 300 days.

Other methods of preconditioning are being investigated to mitigate ischemic brain injury without the use of ischemia itself as the preconditioning insult. Indeed, hypothermia itself has been shown in an animal model to provide a preconditioning type of neuroprotection [259]. Moreover, multiple preclinical studies have shown that partial caloric restriction or ketogenic diet appears to also induce a preconditioning-type of 
neuroprotection from ischemic injury [260, 261]. In fact, our group has recently shown in an animal model that ultrashort (overnight) caloric restriction before asphyxial CA induces mild ketosis and provides significant neuroprotection that may signify a preconditioning-type of effect [262].

\section{Conclusion}

HIBI caused by CA is a complex mechanism of brain damage caused by insults including oxygen deprivation, reduction in cerebral perfusion, and cytotoxicity [2, 263]. For decades the clinical exam was the principal method for determining injury severity and predicting neurological outcome. Electrophysiology, brain imaging, and molecular biomarkers are beginning to be integrated together to increase diagnostic and prognostic accuracy. Clinicians are often conflicted about when to discuss early predictions of outcome for neurologically impaired and comatose patients with family members to elucidate treatment plans [264]. Therefore, multimodal monitoring approaches are highly recommended as potential means of minimizing "self-fulfilling prophecy" and avoiding premature withdrawal of life-sustaining therapy $[121,130]$. Emerging monitoring tools such as diffuse optical technologies, which can provide continuous monitoring of HIBI-related perturbations to the brain, may provide earlier diagnosis/prognosis, more accurate assessment of injury, lower false predictive rates, and better-informed patient treatment. Identifying poor prognosis early on with novel monitoring tools could be vital to either provide prompt treatment or improve outcome by ameliorating physiologic insults as they are occurring or having critical discussions with family members about goals of care.

There have been few recent therapeutic advancements in CA patient treatment, and while existing therapies (e.g., TTM) provide some benefit, there is an urgent need to further reduce devastating outcomes for patients and their families $[5,68]$. For TTM, the number of patients needed to treat in order to improve recovery for one patient is $\sim 6$, making us turn toward the investigation of other potential treatments to further reduce morbidity and mortality [265]. Emerging therapies targeting metabolic factors, pharmacologic therapies, ROS scavengers, preconditioning, and optimizing peripheral blood pressure, $\mathrm{CBF}$, and brain oxygenation may be integrated with the current standards of treatment early on to improve patient outcomes (Fig. 4). Our group anticipates that future therapies will potentially incorporate advanced monitoring tools to collect continuous, quantitative cerebral hemodynamic information at the bedside that may provide real-time feedback to inform dynamic, patient-specific, brain-centered treatment plans and address physiologic changes within minutes of cardiac arrest.
Acknowledgments Support for this work was provided by the Roneet Carmell Memorial Endowment Fund to Y.A., the Arnold and Mabel Beckman Foundation, the National Science Foundation Graduate Research Fellowship Program (DGE-1321846, to C.C.), the United States National Institutes of Health (P41EB015890), and the National Center for Research Resources and National Center for Advancing Translational Sciences, National Institutes of Health, through the following grants: TL1 TR001415-01 to R. H.W., R21 EB024793 to Y. A., KL2 TR001416 to Y.A. via UL1 TR001414, and a CTSA pilot grant to Y.A. via UL1 TR001414. The content is solely the responsibility of the authors and does not necessarily represent the official views of the NIH.

\section{References}

1. Benjamin EJ, Virani SS, Callaway CW, Chamberlain AM, Chang AR, Cheng S, et al. Heart Disease and Stroke Statistics-2018 Update: A Report From the American Heart Association. Circulation 2018;137. https://doi.org/10.1161/CIR. 0000000000000558.

2. Arciniegas DB. Hypoxic-ischemic brain injury: Addressing the disconnect between pathophysiology and public policy. NeuroRehabilitation 2010;26:1-4. https://doi.org/10.3233/NRE2010-0530.

3. Wijdicks EFM, Hijdra A, Young GB, Bassetti CL, Wiebe S. Practice Parameter: Prediction of outcome in comatose survivors after cardiopulmonary resuscitation (an evidence-based review): Report of the Quality Standards Subcommittee of the American Academy of Neurology. Neurology 2006;67:203-10. https://doi. org/10.1212/01.wnl.0000227183.21314.cd.

4. Nolan JP, Soar J, Cariou A, Cronberg T, Moulaert VRM, Deakin $\mathrm{CD}$, et al. European Resuscitation Council and European Society of Intensive Care Medicine Guidelines for Post-resuscitation Care 2015. Section 5 of the European Resuscitation Council Guidelines for Resuscitation 2015. Resuscitation 2015;95:202-22. https:// doi.org/10.1016/j.resuscitation.2015.07.018.

5. Wartenberg KE, Hwang DY, Haeusler KG, Muehlschlegel S, Sakowitz OW, Madžar D, et al. Gap Analysis Regarding Prognostication in Neurocritical Care: A Joint Statement from the German Neurocritical Care Society and the Neurocritical Care Society. Neurocrit Care 2019;31:231-44. https://doi.org/10. 1007/s12028-019-00769-6.

6. Siesjö BK. Cell damage in the brain: a speculative synthesis. J Cereb Blood Flow Metab 1981;1:155-85. https://doi.org/10. 1038/jcbfm.1981.18.

7. Van Den Brule JMD, Van Der Hoeven JG, Hoedemaekers CWE. Cerebral perfusion and cerebral autoregulation after cardiac arrest. Biomed Res Int 2018;2018. https://doi.org/10.1155/2018/ 4143636.

8. Rossetti AO, Tovar Quiroga DF, Juan E, Novy J, White RD, BenHamouda N, et al. Electroencephalography Predicts Poor and Good Outcomes after Cardiac Arrest: A Two-Center Study. Crit Care Med 2017;45:e674-82. https://doi.org/10.1097/CCM. 0000000000002337.

9. Keller SP, Halperin HR. Cardiac Arrest: the Changing Incidence of Ventricular Fibrillation. Curr Treat Options Cardiovasc Med 2015;17. https://doi.org/10.1007/s11936-015-0392-z.

10. Meaney PA, Nadkarni VM, Kern KB, Indik JH, Halperin HR, Berg RA. Rhythms and outcomes of adult in-hospital cardiac arrest. Crit Care Med 2010;38:101-8. https://doi.org/10.1097/CCM. 0b013e3181b43282. 
11. Andrew E, Nehme Z, Lijovic M, Bernard S, Smith K. Outcomes following out-of-hospital cardiac arrest with an initial cardiac rhythm of asystole or pulseless electrical activity in Victoria, Australia. Resuscitation 2014;85:1633-9. https://doi.org/10. 1016/j.resuscitation.2014.07.015.

12. Strömsöe A, Svensson L, Axelsson ÅB, Claesson A, Göransson $\mathrm{KE}$, Nordberg P, et al. Improved outcome in Sweden after out-ofhospital cardiac arrest and possible association with improvements in every link in the chain of survival. Eur Heart J 2015;36:863-71. https://doi.org/10.1093/eurheartj/ehu240.

13. Wissenberg M, Lippert FK, Folke F, Weeke P, Hansen CM, Christensen EF, et al. Association of national initiatives to improve cardiac arrest management with rates of bystander intervention and patient survival after out-of-hospital cardiac arrest. JAMA - J Am Med Assoc 2013;310:1377-84. https://doi.org/ 10.1001/jama.2013.278483.

14. McHugh TP, Stout M. Near-hanging injury. Ann Emerg Med 1983;12:774-6. https://doi.org/10.1016/S0196-0644(83)80256$\mathrm{X}$.

15. Vaagenes P, Safar P, Moossy J, Rao G, Diven W, Ravi C, et al. Asphyxiation versus ventricular fibrillation cardiac arrest in dogs. Resuscitation 1997;35:41-52. https://doi.org/10.1016/S03009572(97)01108-8.

16. Uray T, Lamade A, Elmer J, Drabek T, Stezoski JP, Missé A, et al. Phenotyping Cardiac Arrest. Crit Care Med 2018;46:e508-15. https://doi.org/10.1097/CCM.0000000000003070.

17. Bergström M, Schmidbauer S, Herlitz J, Rawshani A, Friberg H. Pulseless electrical activity is associated with improved survival in out-of-hospital cardiac arrest with initial non-shockable rhythm. Resuscitation 2018;133:147-52. https://doi.org/10.1016/j. resuscitation.2018.10.018.

18. Sekhon MS, Ainslie PN, Griesdale DE. Clinical pathophysiology of hypoxic ischemic brain injury after cardiac arrest: A "two-hit" model. Crit Care 2017;21:1-10. https://doi.org/10.1186/s13054017-1670-9.

19. Buunk G, van der Hoeven JG, Meinders AE. Cerebrovascular reactivity in comatose patients resuscitated from a cardiac arrest. Stroke 1997;28:1569-73. https://doi.org/10.1161/01.str.28.8. 1569.

20. Lemiale V, Huet O, Vigué B, Mathonnet A, Spaulding C, Mira J, et al. Changes in cerebral blood flow and oxygen extraction during post-resuscitation syndrome. Resuscitation 2008;76:17-24. https://doi.org/10.1016/j.resuscitation.2007.06.028.

21. Lassen NA. The luxury-perfusion syndrome and its possible relation to acute metabolic acidosis localised within the brain. Lancet 1966;288:1113-5. https://doi.org/10.1016/s0140-6736(66)921994.

22. Beckstead JE, Tweed WA, Lee J, MacKeen WL. Cerebral blood flow and metabolism in man following cardiac arrest. Stroke 1978;9:569-73. https://doi.org/10.1161/01.STR.9.6.569.

23. Iordanova B, Li L, Clark RSB, Manole MD. Alterations in Cerebral Blood Flow after Resuscitation from Cardiac Arrest. Front Pediatr 2017;5. https://doi.org/10.3389/fped.2017.00174.

24. Ames A, Wright RL, Kowada M, Thurston JM, Majno G. Cerebral ischemia. II. The no-reflow phenomenon. Am J Pathol 1968;52:437-53.

25. Fischer M, Hossmann KA. No-reflow after cardiac arrest. Intensive Care Med 1995;21:132-41. https://doi.org/10.1007/ BF01726536.

26. Hossmann K-A A. Reperfusion of the brain after global ischemia: hemodynamic disturbances. Shock 1997;8:95-101; discussion 102-3. https://doi.org/10.1097/00024382-199708000-00004.

27. Li L, Poloyac SM, Watkins SC, St. Croix CM, Alexander H, Gibson GA, et al. Cerebral microcirculatory alterations and the no-reflow phenomenon in vivo after experimental pediatric cardiac arrest. J Cereb Blood Flow Metab 2019;39:913-25. https://doi.org/10.1177/0271678X17744717.

28. Bacic F, Uematsu S, McCarron RM, Spatz M. Secretion of Immunoreactive endothelin-1 by capillary and microvascular endothelium of human brain. Neurochem Res 1992;17:699-702. https://doi.org/10.1007/BF00968008.

29. van den Brule JMD, Vinke E, van Loon LM, van der Hoeven JG, Hoedemaekers CWE. Middle cerebral artery flow, the critical closing pressure, and the optimal mean arterial pressure in comatose cardiac arrest survivors-An observational study. Resuscitation 2017;110:85-9. https://doi.org/10.1016/j. resuscitation.2016.10.022.

30. Strandgaard S. Autoregulation of cerebral blood flow in hypertensive patients. The modifying influence of prolonged antihypertensive treatment on the tolerance to acute, drug induced hypotension. Circulation 1976;53:720-7. https://doi.org/10.1161/01.CIR.53.4. 720.

31. Sundgreen C, Larsen FS, Herzog TM, Knudsen GM, Boesgaard $\mathrm{S}$, Aldershvile J. Autoregulation of cerebral blood flow in patients resuscitated from cardiac arrest. Stroke 2001;32:128-32. https:// doi.org/10.1161/01.STR.32.1.128.

32. Lee JK, Brady KM, Mytar JO, Kibler KK, Carter EL, Hirsch KG, et al. Cerebral blood flow and cerebrovascular autoregulation in a swine model of pediatric cardiac arrest and hypothermia*. Crit Care Med 2011;39:2337-45. https://doi.org/10.1097/CCM. 0b013e318223b910.

33. Bhate TD, McDonald B, Sekhon MS, Griesdale DEG. Association between blood pressure and outcomes in patients after cardiac arrest: A systematic review. Resuscitation 2015;97: 1-6. https://doi.org/10.1016/j.resuscitation.2015.08.023.

34. Roberts BW, Hope Kilgannon J, Hunter BR, Puskarich MA, Pierce L, Donnino M, et al. Association between early hyperoxia exposure after resuscitation from cardiac arrest and neurological disability: Prospective multicenter protocol-directed cohort study. Circulation 2018;137:2114-24. https://doi.org/10.1161/ CIRCULATIONAHA.117.032054.

35. Takagi S, Cocito L, Hossmann KA. Blood recirculation and pharmacological responsiveness of the cerebral vasculature following prolonged ischemia of cat brain. Stroke 1977;8:707-12. https:// doi.org/10.1161/01.STR.8.6.707.

36. Siesjö BK, Plum F. Cerebral Energy Metabolism in Normoxia and in Hypoxia. Acta Anaesthesiol Scand 1971;15:81-101. https:// doi.org/10.1111/j.1399-6576.1971.tb00662.x.

37. Humphreys SA, Koss MC. Role of nitric oxide in post-ischemic cerebral hyperemia in anesthetized rats. Eur J Pharmacol 1998;347:223-9. https://doi.org/10.1016/S0014-2999(98)001009.

38. Sciotti VM, Van Wylen DGL. Increases in interstitial adenosine and cerebral blood flow with inhibition of adenosine kinase and adenosine deaminase. J Cereb Blood Flow Metab 1993;13:201-7. https://doi.org/10.1038/jcbfm.1993.24.

39. Kågström E, Smith M-LL, Siesjö BK, Kagstrom E, Smith M-LL, Siesjo BK. Local cerebral blood flow in the recovery period following complete cerebral ischemia in the rat. J Cereb Blood Flow Metab 1983;3:170-82. https://doi.org/10.1038/jcbfm.1983.24.

40. Safar P, Stezoski W, Nemoto EM. Amelioration of Brain Damage After 12 Minutes' Cardiac Arrest in Dogs. Arch Neurol 1976;33: 91-5. https://doi.org/10.1001/archneur.1976.00500020019004.

41. Iadecola C, Pelligrino DA, Moskowitz MA, Lassen NA. Nitric oxide synthase inhibition and cerebrovascular regulation. J Cereb Blood Flow Metab 1994;14:175-92. https://doi.org/10. 1038/jcbfm.1994.25.

42. Bisschops LLA, Hoedemaekers CWE, Simons KS, Van Der Hoeven JG. Preserved metabolic coupling and cerebrovascular reactivity during mild hypothermia after cardiac arrest. Crit Care 
Med 2010;38:1542-7. https://doi.org/10.1097/CCM. 0b013e3181e2cc1e.

43. Callaway CW, Donnino MW, Fink EL, Geocadin RG, Golan E, Kern KB, et al. Part 8: Post-cardiac arrest care: 2015 American Heart Association guidelines update for cardiopulmonary resuscitation and emergency cardiovascular care. Circulation 2015;132: S465-82. https://doi.org/10.1161/CIR.0000000000000262.

44. Roberts BW, Kilgannon JH, Hunter BR, Puskarich MA, Shea L, Donnino M, et al. Association Between Elevated Mean Arterial Blood Pressure and Neurologic Outcome After Resuscitation From Cardiac Arrest: Results From a Multicenter Prospective Cohort Study. Crit Care Med 2019;47:93-100. https://doi.org/10. 1097/CCM.0000000000003474.

45. Mölström S, Nielsen TH, Nordström CH, Hassager C, Møller JE, Kjærgaard J, et al. Design paper of the "blood pressure targets in post-resuscitation care and bedside monitoring of cerebral energy state: A randomized clinical trial" Trials 2019;20. https://oi.org/ 10.1186/s13063-019-3397-1.

46. Russo JJ, Di Santo P, Simard T, James TE, Hibbert B, Couture E, et al. Optimal mean arterial pressure in comatose survivors of outof-hospital cardiac arrest: An analysis of area below blood pressure thresholds. Resuscitation 2018;128:175-80. https://doi.org/ 10.1016/j.resuscitation.2018.04.028.

47. Wagner SR, Lanier WL. Metabolism of glucose, glycogen, and high-energy phosphates during complete cerebral ischemia. A comparison of normoglycemic, chronically hyperglycemic diabetic, and acutely hyperglycemic nondiabetic rats. Anesthesiology 1994;81:1516-26. https://doi.org/10.1097/00000542199412000-00028.

48. Hoxworth JM, Xu K, Zhou Y, David Lust WD, Lamanna JC. Cerebral metabolic profile, selective neuron loss, and survival of acute and chronic hyperglycemic rats following cardiac arrest and resuscitation. Brain Res 1999; 821(2):467-79. https://doi.org/10. 1016/S0006-8993(98)01332-8.

49. Greer DM. Mechanisms of injury in hypoxic-ischemic encephalopathy: Implications to therapy. Semin Neurol 2006;26:373-9. https://doi.org/10.1055/s-2006-948317.

50. Holzer M. Targeted temperature management for comatose survivors of cardiac arrest. N Engl J Med 2010;363:1256-64. https:// doi.org/10.1056/NEJMct1002402.

51. Michenfelder JD, Theye RA. The effects of anesthesia and hypothermia on canine cerebral ATP and lactate during anoxia produced by decapitation. Anesthesiology 1970;33:430-9. https:// doi.org/10.1097/00000542-197010000-00013.

52. Silver IA, Erecińska M. Ion homeostasis in rat brain in vivo: Intraand extracellular $[\mathrm{Ca} 2+]$ and $[\mathrm{H}+]$ in the hippocampus during recovery from short-term, transient ischemia. J Cereb Blood Flow Metab 1992;12:759-72. https://doi.org/10.1038/jcbfm. 1992.107.

53. Karen Birmingham. Future of neuroprotective drugs in doubt. Nat Med 2002;8(1):5-5. https://doi.org/10.1038/nm0102-5a.

54. Ikonomidou C, Turski L. Why did NMDA receptor antagonists fail clinical trials for stroke and traumatic brain injury? Lancet Neurol 2002;1:383-6. https://doi.org/10.1016/S1474-4422(02) 00164-3.

55. Nolan JP, Neumar RW, Adrie C, Aibiki M, Berg RA, Böttiger BW, et al. Post-cardiac arrest syndrome: Epidemiology, pathophysiology, treatment, and prognostication. A Scientific Statement from the International Liaison Committee on Resuscitation; the American Heart Association Emergency Cardiovascular Care Committee; the Coun. Resuscitation 2008;79:350-79. https://doi. org/10.1016/j.resuscitation.2008.09.017.

56. Sanganalmath SK, Gopal P, Parker JCJRJCJR, Downs RK, Parker JCJRJCJR, Dawn B. Global cerebral ischemia due to circulatory arrest: insights into cellular pathophysiology and diagnostic modalities. Mol Cell Biochem 2017;426:111-27. https://oi.org/ 10.1007/s11010-016-2885-9.

57. Adams JA. Endothelium and cardiopulmonary resuscitation. Crit. Care Med., vol. 34, 2006. https://doi.org/10.1097/01.CCM. 0000246012.68479 .49 .

58. Fischer M, Böttiger BW, Popov-Cenic S, Hossmann KA. Thrombolysis using plasminogen activator and heparin reduces cerebral no-reflow after resuscitation from cardiac arrest: An experimental study in the cat. Intensive Care Med 1996;22:1214 23. https://doi.org/10.1007/BF01709339.

59. Kacimi R, Giffard RG, Yenari MA. Endotoxin-activated microglia injure brain derived endothelial cells via NF-KB, JAK-STAT and JNK stress kinase pathways. J Inflamm 2011;8. https://doi.org/10. 1186/1476-9255-8-7.

60. Ma Y, Wang J, Wang Y, Yang GY. The biphasic function of microglia in ischemic stroke. Prog Neurobiol 2017;157:247-72. https://doi.org/10.1016/j.pneurobio.2016.01.005.

61. Cao W, Carney JM, Duchon A, Floyd RA, Chevion M. Oxygen free radical involvement in ischemia and reperfusion injury to brain. Neurosci Lett 1988;88:233-8. https://doi.org/10.1016/ 0304-3940(88)90132-2.

62. Hamilton J, Brustovetsky T, Rysted JE, Lin Z, Usachev YM, Brustovetsky N. Deletion of mitochondrial calcium uniporter incompletely inhibits calcium uptake and induction of the permeability transition pore in brain mitochondria. J Biol Chem 2018;293:15652-63. https://doi.org/10.1074/jbc.RA118.002926.

63. Qiu J, Tan YW, Hagenston AM, Martel MA, Kneisel N, Skehel PA, et al. Mitochondrial calcium uniporter Mcu controls excitotoxicity and is transcriptionally repressed by neuroprotective nuclear calcium signals. Nat Commun 2013;4:1-12. https://doi. org/10.1038/ncomms3034.

64. Medvedeva Y V., Lin B, Shuttleworth CW, Weiss JH. Intracellular $\mathrm{Zn} 2+$ accumulation contributes to synaptic failure, mitochondrial depolarization, and cell death in an acute slice oxygen-glucose deprivation model of ischemia. J Neurosci 2009;29:1105-14. https://doi.org/10.1523/JNEUROSCI.4604-08.2009.

65. Yin HZ, Wang HL, Ji SG, Medvedeva Y V., Tian G, Bazrafkan AK, et al. Rapid Intramitochondrial Zn2+ Accumulation in CA1 Hippocampal Pyramidal Neurons After Transient Global Ischemia: A Possible Contributor to Mitochondrial Disruption and Cell Death. J Neuropathol Exp Neurol 2019;78:655-64. https://doi.org/10.1093/jnen/nlz042.

66. Giulian D, Li J, Leara B, Keenen C. Phagocytic microglia release cytokines and cytotoxins that regulate the survival of astrocytes and neurons in culture. Neurochem Int 1994;25:227-33. https:// doi.org/10.1016/0197-0186(94)90066-3.

67. Barone FC, Hillegass LM, Price WJ, White RF, Lee E V., Feuerstein GZ, et al. Polymorphonuclear leukocyte infiltration into cerebral focal ischemic tissue: Myeloperoxidase activity assay and histologic verification. J Neurosci Res 1991;29:336-45. https://doi.org/10.1002/jnr.490290309.

68. Zhang C, Brandon NR, Koper K, Tang P, Xu Y, Dou H. Invasion of peripheral immune cells into brain parenchyma after cardiac arrest and resuscitation. Aging Dis 2018;9:412-25. https://doi. org/10.14336/AD.2017.0926.

69. Qin C, Zhou LQ, Ma XT, Hu ZW, Yang S, Chen M, et al. Dual Functions of Microglia in Ischemic Stroke. Neurosci Bull 2019. https://doi.org/10.1007/s12264-019-00388-3.

70. Kim JY, Kim N, Yenari MA. Mechanisms and Potential Therapeutic Applications of Microglial Activation after Brain Injury. CNS Neurosci Ther 2015;21:309-19. https://doi.org/10. 1111/cns. 12360.

71. Walter L, Neumann H. Role of microglia in neuronal degeneration and regeneration. Semin Immunopathol 2009;31:513-25. https:// doi.org/10.1007/s00281-009-0180-5. 
72. Dabrowska S, Andrzejewska A, Lukomska B, Janowski M. Neuroinflammation as a target for treatment of stroke using mesenchymal stem cells and extracellular vesicles. J Neuroinflammation 2019;16. https://doi.org/10.1186/s12974019-1571-8.

73. Pluta R, Lossinsky AS, Wiśniewski HM, Mossakowski MJ. Early blood-brain barrier changes in the rat following transient complete cerebral ischemia induced by cardiac arrest. Brain Res 1994;633: 41-52. https://doi.org/10.1016/0006-8993(94)91520-2.

74. Egashira Y, Suzuki Y, Azuma Y, Takagi T, Mishiro K, Sugitani S, et al. The growth factor progranulin attenuates neuronal injury induced by cerebral ischemia-reperfusion through the suppression of neutrophil recruitment. J Neuroinflammation 2013;10. https:// doi.org/10.1186/1742-2094-10-105.

75. Jackman K, Kahles T, Lane D, Garcia-Bonilla L, Abe T, Capone $\mathrm{C}$, et al. Progranulin deficiency promotes post-ischemic bloodbrain barrier disruption. J Neurosci 2013;33:19579-89. https:// doi.org/10.1523/JNEUROSCI.4318-13.2013.

76. Kanazawa M, Kawamura K, Takahashi T, Miura M, Tanaka Y, Koyama M, et al. Multiple therapeutic effects of progranulin on experimental acute ischaemic stroke. Brain 2015;138:1932-48. https://doi.org/10.1093/brain/awv079.

77. Mizuma A, Yenari MA. Anti-inflammatory targets for the treatment of reperfusion injury in stroke. Front Neurol 2017;8. https:// doi.org/10.3389/fneur.2017.00467.

78. Xiao F, Arnold TC, Zhang S, Brown C, Steven Alexander J, Carden DL, et al. Cerebral cortical aquaporin-4 expression in brain edema following cardiac arrest in rats. Acad Emerg Med 2004;11: 1001-7. https://doi.org/10.1197/j.aem.2004.05.026.

79. Wallisch JS, Janesko-Feldman K, Alexander H, Jha RM, Farr GW, McGuirk PR, et al. The aquaporin-4 inhibitor AER-271 blocks acute cerebral edema and improves early outcome in a pediatric model of asphyxial cardiac arrest. Pediatr Res 2019;85:511-7. https://doi.org/10.1038/s41390-018-0215-5.

80. Hayman EG, Patel AP, Kimberly WT, Sheth KN, Simard JM. Cerebral Edema After Cardiopulmonary Resuscitation: A Therapeutic Target Following Cardiac Arrest? Neurocrit Care 2018;28:276-87. https://doi.org/10.1007/s12028-017-0474-8.

81. Panickar KS, Noremberg MD. Astrocytes in cerebral ischemic injury: Morphological and general considerations. Glia 2005;50: 287-98. https://doi.org/10.1002/glia.20181.

82. Deng G, Carter J, Traystman RJ, Wagner DH, Herson PS. Proinflammatory T-lymphocytes rapidly infiltrate into the brain and contribute to neuronal injury following cardiac arrest and cardiopulmonary resuscitation. J Neuroimmunol 2014;274:132-40. https://doi.org/10.1016/j.jneuroim.2014.07.009.

83. Huang K, Wang Z, Gu Y, Hu Y, Ji Z, Wang S, et al. Glibenclamide Is Comparable to Target Temperature Management in Improving Survival and Neurological Outcome After Asphyxial Cardiac Arrest in Rats. J Am Heart Assoc 2016;5:1-11. https://doi.org/ 10.1161/JAHA.116.003465.

84. Nakayama S, Taguchi N, Isaka Y, Nakamura T, Tanaka M. Glibenclamide and Therapeutic Hypothermia Have Comparable Effect on Attenuating Global Cerebral Edema Following Experimental Cardiac Arrest. Neurocrit Care 2018;29:119-27. https://doi.org/10.1007/s12028-017-0479-3.

85. Walter EJ, Carraretto M. The neurological and cognitive consequences of hyperthermia. Crit Care 2016;20. https://doi.org/10. 1186/s13054-016-1376-4.

86. Lee BH, Inui D, Suh GY, Kim JY, Kwon JY, Park J, et al. Association of body temperature and antipyretic treatments with mortality of critically ill patients with and without sepsis: Multicentered prospective observational study. Crit Care 2012;16. https://doi.org/10.1186/cc11211.

87. de Jonge JC, Wallet J, van der Worp HB. Fever worsens outcomes in animal models of ischaemic stroke: A systematic review and meta-analysis. Eur Stroke J 2019;4:29-38. https://doi.org/10. 1177/2396987318776421.

88. Kiyatkin EA, Sharma HS. Permeability of the blood-brain barrier depends on brain temperature. Neuroscience 2009;161:926-39. https://doi.org/10.1016/j.neuroscience.2009.04.004.

89. Zlotnik A, Gurevich B, Artru AA, Gruenbaum SE, Dubilet M, Leibowitz A, et al. The effect of hyperthermia on blood glutamate levels. Anesth Analg 2010;111:1497-504. https://doi.org/10. 1213/ANE.0b013e3181fc0112.

90. Campos F, Pérez-Mato M, Agulla J, Blanco M, Barral D, Almeida Á, et al. Glutamate Excitoxicity Is the Key Molecular Mechanism Which Is Influenced by Body Temperature during the Acute Phase of Brain Stroke. PLoS One 2012;7. https://doi.org/10.1371/ journal.pone.0044191.

91. Jackson TC, Kochanek PM. A New Vision for Therapeutic Hypothermia in the Era of Targeted Temperature Management: A Speculative Synthesis. Ther Hypothermia Temp Manag 2019;9:13-47. https://doi.org/10.1089/ther.2019.0001.

92. Anderson CA, Arciniegas DB. Cognitive sequelae of hypoxicischemic brain injury: A review. NeuroRehabilitation 2010;26: 47-63. https://doi.org/10.3233/NRE-2010-0535.

93. Lybeck A, Friberg H, Aneman A, Hassager C, Horn J, Kjærgaard $\mathrm{J}$, et al. Prognostic significance of clinical seizures after cardiac arrest and target temperature management. Resuscitation 2017;114:146-51. https://doi.org/10.1016/j.resuscitation.2017. 01.017 .

94. Walker AC, Johnson NJ. Targeted Temperature Management and Postcardiac arrest Care. Emerg Med Clin North Am 2019;37:38193. https://doi.org/10.1016/j.emc.2019.03.002.

95. Polderman KH. Mechanisms of action, physiological effects, and complications of hypothermia. Crit Care Med 2009;37. https://doi. org/10.1097/CCM.0b013e3181aa5241.

96. Wang Q, Miao P, Modi HR, Garikapati S, Koehler RC, Thakor N $\mathrm{V}$. Therapeutic hypothermia promotes cerebral blood flow recovery and brain homeostasis after resuscitation from cardiac arrest in a rat model. J Cereb Blood Flow Metab 2019;39:1961-73. https:// doi.org/10.1177/0271678X18773702.

97. Gunn AJ, Laptook AR, Robertson NJ, Barks JD, Thoresen M, Wassink G, et al. Therapeutic hypothermia translates from ancient history in to practice. Pediatr Res 2017;81:202-9. https://doi.org/ 10.1038/pr.2016.198.

98. Tooley JR, Satas S, Porter H, Silver IA, Thoresen M. Head cooling with mild systemic hypothermia in anesthetized piglets is neuroprotective. Ann Neurol 2003;53:65-72. https://doi.org/10.1002/ ana.10402.

99. Wassink G, Gunn ER, Drury PP, Bennet L, Gunn AJ. The mechanisms and treatment of asphyxial encephalopathy. Front Neurosci 2014;8:1-11. https://doi.org/10.3389/fnins.2014.00040.

100. Sun YJ, Zhang ZY, Fan B, Li GY. Neuroprotection by therapeutic hypothermia. Front Neurosci 2019;13:1-11. https://doi.org/10. 3389/fnins.2019.00586.

101. Laptook AR, Corbett RJ, Sterett R, Garcia D, Tollefsbol G. Quantitative relationship between brain temperature and energy utilization rate measured in vivo using $31 \mathrm{P}$ and $1 \mathrm{H}$ magnetic resonance spectroscopy. Pediatr Res 1995;38:919-25. https://doi. org/10.1203/00006450-199512000-00015.

102. Rosomoff HL, Holaday DA. Cerebral blood flow and cerebral oxygen consumption during hypothermia. Am J Physiol 1954;179:85-8. https://doi.org/10.1152/ajplegacy.1954.179.1.85.

103. Khalilov RA, Dzhafarova AM, Khizrieva SI. Effect of Hypothermia on Kinetic Characteristics of Lactate Dehydrogenase in Rat Brain under Conditions of Global Ischemia and Reperfusion. Bull Exp Biol Med 2017;163:334-7. https://doi.org/10.1007/s10517-017-3797-8.

104. Busto R, Globus MY, Dietrich WD, Martinez E, Valdés I, Ginsberg MD. Effect of mild hypothermia on ischemia-induced 
release of neurotransmitters and free fatty acids in rat brain. Stroke 1989;20:904-10. https://doi.org/10.1161/01.STR.20.7.904.

105. Nakashima K, Todd MM. Effects of hypothermia on the rate of excitatory amino acid release after ischemic depolarization. Stroke 1996;27:913-8. https://doi.org/10.1161/01.STR.27.5.913.

106. Ooboshi H, Ibayashi S, Takano K, Sadoshima S, Kondo A, Uchimura $\mathrm{H}$, et al. Hypothermia inhibits ischemia-induced efflux of amino acids and neuronal damage in the hippocampus of aged rats. Brain Res. 2000;884(1-2):23-30. https://doi.org/10.1016/ S0006-8993(00)02861-4.

107. Bart RD, Takaoka S, Pearlstein RD, Dexter F, Warner DS. Interactions between hypothermia and the latency to ischemic depolarization: implications for neuroprotection. Anesthesiology 1998;88:1266-73. https://doi.org/10.1097/00000542199805000-00018.

108. McManus T, Sadgrove M, Pringle AK, Chad JE, Sundstrom LE. Intraischaemic hypothermia reduces free radical production and protects against ischaemic insults in cultured hippocampal slices. J Neurochem 2004;91:327-36. https://doi.org/10.1111/j.14714159.2004.02711.x.

109. Lei B, Adachi N, Arai T. The effect of hypothermia on $\mathrm{H} 2 \mathrm{O} 2$ production during ischemia and reperfusion: a microdialysis study in the gerbil hippocampus. Neurosci Lett 1997;222:91-4. https:// doi.org/10.1016/S0304-3940(97)13349-3.

110. Baumann E, Preston E, Slinn J, Stanimirovic D. Post-ischemic hypothermia attenuates loss of the vascular basement membrane proteins, agrin and SPARC, and the blood-brain barrier disruption after global cerebral ischemia. Brain Res 2009;1269:185-97. https://doi.org/10.1016/j.brainres.2009.02.062.

111. Akbari Y, Mulder M, Razmara A, Geocadin R. Cool Down the Inflammation: Hypothermia as a Therapeutic Strategy for Acute Brain Injuries. Immunol. Mech. Ther. Brain Inj. Stroke. Chen J, Hu X, Stenzel-Poore M, Zhang JH, editors. New York, NY: Springer New York; 2014. Chapter 19 p.349-375. https://doi. org/10.1007/978-1-4614-8915-3.

112. Webster CM, Kelly S, Koike MA, Chock VY, Giffard RG, Yenari MA. Inflammation and NFKB activation is decreased by hypothermia following global cerebral ischemia. Neurobiol Dis 2009;33: 301-12. https://doi.org/10.1016/j.nbd.2008.11.001.

113. Eberspächer E, Werner C, Engelhard K, Pape M, Laacke L, Winner D, et al. Long-term effects of hypothermia on neuronal cell death and the concentration of apoptotic proteins after incomplete cerebral ischemia and reperfusion in rats. Acta Anaesthesiol Scand 2005;49:477-87. https://doi.org/10.1111/j.1399-6576. 2005.00649.x.

114. Vitkovic L, Maeda S, Sternberg E. Anti-inflammatory cytokines: Expression and action in the brain. Neuroimmunomodulation 2001;9:295-312. https://doi.org/10.1159/000059387.

115. Stahel PP, Yatsiv I, Morganti-Kossmann MC, Ferez D, Novick D, Rubinstein M, et al. Elevated intracranial il-18 and evidence of neuroprotective effects of IL-18 binding protein (IL-18bp) after experimental closed head injury. Langenbeck's Arch Surg 2001;386:474-5.

116. Hofstetter C, Boost KA, Flondor M, Basagan-Mogol E, Betz C, Homann $\mathrm{M}$, et al. Anti-inflammatory effects of sevoflurane and mild hypothermia in endotoxemic rats. Acta Anaesthesiol Scand 2007;51:893-9. https://doi.org/10.1111/j.1399-6576.2007.01353. $\mathrm{x}$.

117. Huet O, Kinirons B, Dupic L, Lajeunie E, Mazoit JX, Benhamou $\mathrm{D}$, et al. Induced mild hypothermia reduces mortality during acute inflammation in rats. Acta Anaesthesiol Scand 2007;51:1211-6. https://doi.org/10.1111/j.1399-6576.2007.01419.x.

118. Polderman KH, Herold I. Therapeutic hypothermia and controlled normothermia in the intensive care unit: Practical considerations, side effects, and cooling methods. Crit Care Med 2009;37:110120. https://doi.org/10.1097/CCM.0b013e3181962ad5.
119. Frank SM, Satitpunwaycha P, Bruce SR, Herscovitch P, Goldstein DS. Increased myocardial perfusion and sympathoadrenal activation during mild core hypothermia in awake humans. Clin Sci 2003;104(5):503-8. https://doi.org/10.1042/CS20020256.

120. Nabel EG, Ganz P, Gordon JB, Alexander RW, Selwyn AP. Dilation of normal and constriction of atherosclerotic coronary arteries caused by the cold pressor test. Circulation 1988;77:4352. https://doi.org/10.1161/01.cir.77.1.43.

121. Zhou SE, Maciel CB, Ormseth CH, Beekman R, Gilmore EJ, Greer DM. Distinct predictive values of current neuroprognostic guidelines in post-cardiac arrest patients. Resuscitation 2019;139: 343-50. https://doi.org/10.1016/j.resuscitation.2019.03.035.

122. Kavi T, Desai M, Yilmaz FM, Kakadia B, Burakgazi-Dalkilic E, Shrestha GS. Inter-predictability of Neuroprognostic Modalities After Cardiac Arrest. Cureus 2019;11. https://doi.org/10.7759/ cureus. 4489 .

123. Greer DM, Rosenthal ES, Wu O. Neuroprognostication of hypoxic-ischaemic coma in the therapeutic hypothermia era. Nat Rev Neurol 2014;10:190-203. https://doi.org/10.1038/ nrneurol.2014.36.

124. Sandroni C, D'Arrigo S. Neurologic prognostication: Neurologic examination and current guidelines. Semin Neurol 2017;37:40-7. https://doi.org/10.1055/s-0036-1593857.

125. Eertmans W, Tran TMP, Genbrugge C, Peene L, Mesotten D, Dens J, et al. A prediction model for good neurological outcome in successfully resuscitated out-of-hospital cardiac arrest patients. Scand J Trauma Resusc Emerg Med 2018;26. https://doi.org/10. 1186/s13049-018-0558-2.

126. Willoughby JO, Leach BG. Relation of Neurological Findings after Cardiac Arrest to Outcome. BMJ 1974;3:437-9. https://doi. org/10.1136/bmj.3.5928.437.

127. Snyder BD, Ramirez-Lassepas M, Lippert DM. Article abstract Neurologic status and prognosis after cardiopulmonary arrest: 1 . A retrospective study. Neurology 1977;27(9):807-807. https://doi. org/10.1212/WNL.27.9.807.

128. Levy DE, Caronna JJ, Singer BH, Lapinski RH, Frydman H, Plum F. Predicting Outcome From Hypoxic-lschemic Coma. JAMA J Am Med Assoc 1985;253:1420. https://doi.org/10.1001/jama. 1985.03350340072020.

129. Perkins GD, Jacobs IG, Nadkarni VM, Berg RA, Bhanji F, Biarent $\mathrm{D}$, et al. Cardiac arrest and cardiopulmonary resuscitation outcome reports: Update of the Utstein resuscitation registry templates for out-of-hospital cardiac arrest: A statement for healthcare professionals from a task force of the international liaison committee . Circulation 2015;132:1286-300. https://doi.org/10.1161/CIR. 0000000000000144.

130. Sandroni C, D'Arrigo S, Nolan JP. Prognostication after cardiac arrest. Crit Care 2018;22:1-9. https://doi.org/10.1186/s13054018-2060-7.

131. Riker RR, Sawyer ME, Fischman VG, May T, Lord C, Eldridge A, et al. Neurological Pupil Index and Pupillary Light Reflex by Pupillometry Predict Outcome Early After Cardiac Arrest. Neurocrit Care 2019. https://doi.org/10.1007/s12028-019-007174.

132. Oddo M, Friberg H. Neuroprognostication after cardiac arrest in the light of targeted temperature management. Curr Opin Crit Care 2017;23:244-50. https://doi.org/10.1097/MCC. 0000000000000406

133. Torbey MT, Selim M, Knorr J, Bigelow C, Recht L. Quantitative analysis of the loss of distinction between gray and white matter in comatose patients after cardiac arrest. Stroke 2000;31:2163-7. https://doi.org/10.1161/01.STR.31.9.2163.

134. Yanagawa Y, Un-No Y, Sakamoto T, Okada Y. Cerebral density on CT immediately after a successful resuscitation of cardiopulmonary arrest correlates with outcome. Resuscitation 2005;64:97101. https://doi.org/10.1016/j.resuscitation.2004.06.015. 
135. Choi SP, Park HK, Park KN, Kim YM, Ahn KJ, Choi KH, et al. The density ratio of grey to white matter on computed tomography as an early predictor of vegetative state or death after cardiac arrest. Emerg Med J 2008;25:666-9. https://doi.org/10.1136/emj. 2007.053306

136. Metter RB, Rittenberger JC, Guyette FX, Callaway CW. Association between a quantitative CT scan measure of brain edema and outcome after cardiac arrest. Resuscitation 2011;82: 1180-5. https://doi.org/10.1016/j.resuscitation.2011.04.001.

137. Wu O, Batista LM, Lima FO, Vangel MG, Furie KL, Greer DM. Predicting clinical outcome in comatose cardiac arrest patients using early noncontrast computed tomography. Stroke 2011;42: 985-92. https://doi.org/10.1161/STROKEAHA.110.594879.

138. Hun D. Combining brain computed tomography and serum neuron specific enolase improves the prognostic performance compared to either alone in comatose cardiac arrest survivors treated with therapeutic hypothermia. Resuscitation 2013;84:1387-92. https://doi.org/10.1016/j.resuscitation.2013.05.026.

139. Silva S, Peran P, Kerhuel L, Malagurski B, Chauveau N, Bataille B, et al. Brain gray matter MRI morphometry for neuroprognostication after cardiac arrest. Crit Care Med 2017;45:e763-71. https://doi.org/ 10.1097/CCM.0000000000002379.

140. Greer D, Scripko P, Bartscher J, Sims J, Camargo E, Singhal A, et al. Clinical MRI interpretation for outcome prediction in cardiac arrest. Neurocrit Care 2012;17:240-4. https://doi.org/10.1007/ s12028-012-9716-y.

141. Hirsch KG, Mlynash M, Eyngorn I, Pirsaheli R, Okada A, Komshian S, et al. Multi-Center Study of Diffusion-Weighted Imaging in Coma After Cardiac Arrest. Neurocrit Care 2016;24: 82-9. https://doi.org/10.1007/s12028-015-0179-9.

142. Hirsch KG, Mlynash M, Jansen S, Persoon S, Eyngorn I, Krasnokutsky M V., et al. Prognostic Value of A Qualitative Brain MRI Scoring System After Cardiac Arrest. J Neuroimaging 2015;25:430-7. https://doi.org/10.1111/jon. 12143.

143. Oren NC, Chang E, Yang CWY, Lee SK. Brain Diffusion Imaging Findings May Predict Clinical Outcome after Cardiac Arrest. J Neuroimaging 2019;29:540-7. https://doi.org/10.1111/jon.12626.

144. Jang J, Oh SH, Nam Y, Lee K, Choi HS, Jung SL, et al. Prognostic value of phase information of $2 \mathrm{D} \mathrm{T} 2 *$-weighted gradient echo brain imaging in cardiac arrest survivors: A preliminary study. Resuscitation 2019;140:142-9. https://doi.org/10.1016/j. resuscitation.2019.05.026.

145. Parra-Morales AM, Rudas J, Vargas JA, Gómez F, Enciso-Olivera $\mathrm{CO}$, Trujillo-Rodriguez D, et al. Structural and functional connectivity of ascending reticular activating system in a patient with impaired consciousness after a cardiac arrest: A case report. Medicine (Baltimore) 2019;98:e15620. https://doi.org/10.1097/ MD.0000000000015620.

146. Jeon CH, Park JS, Lee JH, Kim H, Kim SMSC, Park KH, et al. Comparison of brain computed tomography and diffusionweighted magnetic resonance imaging to predict early neurologic outcome before target temperature management comatose cardiac arrest survivors. Resuscitation 2017;118:21-6. https://doi.org/10. 1016/j.resuscitation.2017.06.021.

147. Mörtberg E, Cumming P, Wiklund L, Rubertsson S. Cerebral metabolic rate of oxygen (CMRO2) in pig brain determined by PET after resuscitation from cardiac arrest. Resuscitation 2009;80:7016. https://doi.org/10.1016/j.resuscitation.2009.03.005.

148. Synek VM. Value of a Revised EEG Coma Scale for Prognosis after Cerebral Anoxia and Diffuse Head Injury. Clin EEG Neurosci 1990;21:25-30. https://doi.org/10.1177/ 155005949002100111

149. Backman S, Cronberg T, Friberg H, Ullén S, Horn J, Kjaergaard J, et al. Highly malignant routine EEG predicts poor prognosis after cardiac arrest in the Target Temperature Management trial.
Resuscitation 2018;131:24-8. https://doi.org/10.1016/j. resuscitation.2018.07.024.

150. Rossetti AO, Oddo M, Logroscino G, Kaplan PW. Prognostication after cardiac arrest and hypothermia: A prospective study. Ann Neurol 2010;67:301-7. https://doi.org/10.1002/ana.21984.

151. Burjek NE, Wagner CE, Hollenbeck RD, Wang L, Yu C, McPherson JA, et al. Early Bispectral Index and Sedation Requirements During Therapeutic Hypothermia Predict Neurologic Recovery Following Cardiac Arrest*. Crit Care Med 2014;42:1204-12. https://doi.org/10.1097/CCM. 0000000000000126.

152. Park JH, Oh JH, Choi SP, Wee JH. Neurologic outcome after outof-hospital cardiac arrest could be predicted with the help of bispectral-index during early targeted temperature management. Scand J Trauma Resusc Emerg Med 2018;26. https://doi.org/10. 1186/s13049-018-0529-7.

153. Hoedemaekers CWE, Abdo WF. Bispectral index for prognostication after cardiac arrest: The holy grail at last? Crit Care Med 2014;42:1312-3. https://doi.org/10.1097/CCM.0000000000000187.

154. Gul SS, Huesgen KW, Wang KK, Mark K, Tyndall JA. Prognostic utility of neuroinjury biomarkers in post out-of-hospital cardiac arrest (OHCA) patient management. Med Hypotheses 2017;105: 34-47. https://doi.org/10.1016/j.mehy.2017.06.016.

155. Stammet P, Collignon O, Hassager C, Wise MP, Hovdenes J, Åneman A, et al. Neuron-specific enolase as a predictor of death or poor neurological outcome after out-of-hospital cardiac arrest and targeted temperature management at $33^{\circ} \mathrm{C}$ and $36^{\circ} \mathrm{C}$. J Am Coll Cardiol 2015;65:2104-14. https://doi.org/10.1016/j.jacc. 2015.03.538.

156. Stammet P, Dankiewicz J, Nielsen N, Fays F, Collignon O, Hassager C, et al. Protein S100 as outcome predictor after outof-hospital cardiac arrest and targeted temperature management at $33{ }^{\circ} \mathrm{C}$ and $36{ }^{\circ} \mathrm{C}$. Crit Care 2017;21. https://doi.org/10.1186/ s13054-017-1729-7.

157. Duez CHV, Grejs AM, Jeppesen AN, Schrøder AD, Søreide E, Nielsen JF, et al. Neuron-specific enolase and S-100b in prolonged targeted temperature management after cardiac arrest: A randomised study. Resuscitation 2018;122:79-86. https://doi.org/ 10.1016/j.resuscitation.2017.11.052.

158. Wiberg S, Hassager C, Stammet P, Winther-Jensen M, Thomsen $\mathrm{JH}$, Erlinge D, et al. Single versus serial measurements of neuronspecific enolase and prediction of poor neurological outcome in persistently unconscious patients after out-of-hospital cardiac arrest - A TTM-trial substudy. PLoS One 2017;12. https://doi.org/ 10.1371/journal.pone.0168894.

159. Jang JH, Park W Bin, Lim YS, Choi JY, Cho JS, Woo JH, et al. Combination of S100B and procalcitonin improves prognostic performance compared to either alone in patients with cardiac arrest: A prospective observational study. Medicine (Baltimore) 2019;98:e14496. https://doi.org/10.1097/MD. 0000000000014496

160. Sandroni C, Cariou A, Cavallaro F, Cronberg T, Friberg H, Hoedemaekers $\mathrm{C}$, et al. Prognostication in comatose survivors of cardiac arrest: An advisory statement from the European Resuscitation Council and the European Society of Intensive Care Medicine. Intensive Care Med 2014;40:1816-31. https:// doi.org/10.1007/s00134-014-3470-x.

161. Boileau A, Somoza AS, Dankiewicz J, Stammet P, Gilje P, Erlinge D, et al. Circulating Levels of miR-574-5p Are Associated with Neurological Outcome after Cardiac Arrest in Women: A Target Temperature Management (TTM) Trial Substudy. Dis Markers 2019;2019:1-10. https://doi.org/10.1155/2019/1802879.

162. O'Sullivan TD, Cerussi AE, Cuccia DJ, Tromberg BJ. Diffuse optical imaging using spatially and temporally modulated light. J Biomed Opt 2012;17:0713111. https://doi.org/10.1117/1.jbo.17.7. 071311. 
163. Stankovic MR, Maulik D, Rosenfeld W, Stubblefield PG, Kofinas $\mathrm{AD}$, Drexler S, et al. Real-time optical imaging of experimental brain ischemia and hemorrhage in neonatal piglets. J Perinat Med 1999;27:279-86. https://doi.org/10.1515/JPM.1999.039.

164. Chang YS, Park WS, Lee M, Kim KS, Shin SM, Choi JH. Near infrared spectroscopic monitoring of secondary cerebral energy failure after transient global hypoxia-ischemia in the newborn piglet. Neurol Res 1999;21:216-24. https://doi.org/10.1080/ 01616412.1999 .11740921$.

165. Sinha N, Parnia S. Monitoring the Brain After Cardiac Arrest: a New Era. Curr Neurol Neurosci Rep 2017;17. https://doi.org/10. 1007/s11910-017-0770-x.

166. Storm C, Leithner C, Krannich A, Wutzler A, Ploner CJ, Trenkmann L, et al. Regional cerebral oxygen saturation after cardiac arrest in 60 patients-A prospective outcome study. Resuscitation 2014;85:1037-41. https://doi.org/10.1016/j. resuscitation.2014.04.021.

167. Genbrugge C, Dens J, Meex I, Boer W, Eertmans W, Sabbe M, et al. Regional Cerebral Oximetry during Cardiopulmonary Resuscitation: Useful or Useless? J Emerg Med 2016;50:198207. https://doi.org/10.1016/j.jemermed.2015.03.043.

168. Cournoyer A, Iseppon M, Chauny JM, Denault A, Cossette S, Notebaert É. Near-infrared Spectroscopy Monitoring During Cardiac Arrest: A Systematic Review and Meta-analysis. Acad Emerg Med 2016;23:851-62. https://doi.org/10.1111/acem. 12980.

169. Sanfilippo F, Serena G, Corredor C, Benedetto U, Maybauer MO, Al-Subaie N, et al. Cerebral oximetry and return of spontaneous circulation after cardiac arrest: A systematic review and meta-analysis. Resuscitation 2015;94:67-72. https://doi.org/10.1016/j. resuscitation.2015.06.023.

170. Wang Q, Miao P, Modi HR, Garikapati S, Koehler RC, Thakor N V. Therapeutic hypothermia promotes cerebral blood flow recovery and brain homeostasis after resuscitation from cardiac arrest in a rat model. J Cereb Blood Flow Metab 2018. https://doi.org/10. 1177/0271678X18773702.

171. Lee JK, Brady KM, Mytar JO, Kibler KK, Carter EL, Hirsch KG, et al. Cerebral blood flow and cerebrovascular autoregulation in a swine model of pediatric cardiac arrest and hypothermia*. Crit Care Med 2011;39:2337-45.

172. Elwell C, Leung T. Oxygen Transport to Tissue XXXVII. Elwell CE, Leung TS, Harrison DK, editors. Advances in Experimental Medicine and Biology. New York, NY: Springer New York. V-Vi. (Advances in Experimental Medicine and Biology; vol. 876). Chapter 19: Detection of ROSC in Patients with Cardiac Arrest During Chest Compression Using NIRS: A Pilot Study 2016;p.151-157. https://doi.org/10.1007/978-1-4939-3023-4.

173. Peters J, Van Wageningen B, Hoogerwerf N, Tan E. Near-Infrared Spectroscopy: A Promising Prehospital Tool for Management of Traumatic Brain Injury. Prehosp Disaster Med 2017;32:414-8. https://doi.org/10.1017/S1049023X17006367.

174. Allen BS, Ko Y, Buckberg GD, Sakhai S, Tan Z. Studies of isolated global brain ischaemia: I. A new large animal model of global brain ischaemia and its baseline perfusion studies. Eur $\mathrm{J}$ Cardio-Thoracic Surg 2012;41:1138-46. https://doi.org/10.1093/ ejcts/ezr316.

175. Ferradal SL, Yuki K, Vyas R, Ha CG, Yi F, Stopp C, et al. Noninvasive assessment of cerebral blood flow and oxygen metabolism in neonates during hypothermic cardiopulmonary bypass: Feasibility and clinical implications. Sci Rep 2017;7:1-9. https:// doi.org/10.1038/srep44117.

176. Dehaes M, Aggarwal A, Lin PY, Rosa Fortuno C, Fenoglio A, Roche-Labarbe N, et al. Cerebral oxygen metabolism in neonatal hypoxic ischemic encephalopathy during and after therapeutic hypothermia. J Cereb Blood Flow Metab 2014;34:87-94. https://doi. org/10.1038/jcbfm.2013.165.
177. Pham P, Bindra J, Chuan A, Jaeger M, Aneman A. Are changes in cerebrovascular autoregulation following cardiac arrest associated with neurological outcome? Results of a pilot study. Resuscitation 2015;96:192-8. https://doi.org/10.1016/j.resuscitation.2015.08. 007.

178. Crouzet C, Wilson RH, Lee D, Bazrafkan A, Tromberg BJ, Akbari Y, et al. Dissociation of Cerebral Blood Flow and Femoral Artery Blood Pressure Pulsatility After Cardiac Arrest and Resuscitation in a Rodent Model: Implications for Neurological Recovery. J Am Heart Assoc 2020;9:e012691. https://doi.org/10.1161/JAHA.119. 012691.

179. Shang Y, Chen L, Toborek M, Yu G. Diffuse optical monitoring of repeated cerebral ischemia in mice. Opt Express 2011;19:20301. https://doi.org/10.1364/oe.19.020301.

180. Farkas E, Bari F, Obrenovitch TP. Multi-modal imaging of anoxic depolarization and hemodynmic changes induced by cardiac arrest in the rat cerebral cortex. Neuroimage 2010;51:734-42. https:// doi.org/10.1016/j.neuroimage.2010.02.055.

181. Bere Z, Obrenovitch TP, Bari F, Farkas E. Ischemia-induced depolarizations and associated hemodynamic responses in incomplete global forebrain ischemia in rats. Neuroscience 2014;260: 217-26. https://doi.org/10.1016/j.neuroscience.2013.12.032.

182. Chalak LF, Zhang R. New Wavelet Neurovascular Bundle for Bedside Evaluation of Cerebral Autoregulation and Neurovascular Coupling in Newborns with Hypoxic-Ischemic Encephalopathy. Dev Neurosci 2017;39:89-96. https://doi.org/ $10.1159 / 000457833$.

183. Sussman CB, Rossignol C, Zhang Q, Jiang H, Zheng T, Steindler $\mathrm{D}$, et al. Photoacoustic tomography can detect cerebral hemodynamic alterations in a neonatal rodent model of hypoxia-ischemia. Acta Neurobiol Exp (Wars) 2012;72:253-63.

184. Konecky SD, Wilson RH, Hagen N, Mazhar A, Tkaczyk TS, Frostig RD, et al. Hyperspectral optical tomography of intrinsic signals in the rat cortex. Neurophotonics 2015;2:045003. https:// doi.org/10.1117/1.nph.2.4.045003.

185. Rummel C, Basciani R, Nirkko A, Schroth G, Stucki M, Reineke $D$, et al. Spatially extended versus frontal cerebral near-infrared spectroscopy during cardiac surgery: a case series identifying potential advantages. J Biomed Opt 2018;23:1. https://doi.org/10. 1117/1.jbo.23.1.016012.

186. Kawauchi S, Sato S, Ooigawa H, Nawashiro H, Ishihara M, Kikuchi M. Light scattering change precedes loss of cerebral adenosine triphosphate in a rat global ischemic brain model. Neurosci Lett 2009;459:152-6. https://doi.org/10.1016/j.neulet. 2009.05.014.

187. Wilson RH, Crouzet C, Torabzadeh M, Bazrafkan A. High-speed spatial frequency domain imaging of rat cortex detects dynamic optical and physiological properties following cardiac arrest and resuscitation. Neurophotonics 2017;4:1. https://doi.org/10.1117/1. nph.4.4.045008.

188. Wilson RH, Crouzet C, Lee DE, Donga DP, Patel AH, Bazrafkan A, et al. Spreading depolarization and repolarization during cardiac arrest as an ultra-early marker of neurological recovery in a preclinical model. BioRxiv [Preprint] 2019. https://doi.org/10. $1101 / 786210$.

189. Crouzet C, Wilson RH, Bazrafkan A, Farahabadi MH, Lee D, Alcocer J, et al. Cerebral blood flow is decoupled from blood pressure and linked to EEG bursting after resuscitation from cardiac arrest. Biomed Opt Express 2016;7:4660. https://doi.org/10. 1364/boe.7.004660.

190. Wilson RH, Crouzet C, Torabzadeh M, Bazrafkan AK, Maki N, Alocer J, et al. Cerebral perfusion and metabolism coupling during a critical time window provides rapid assessment of cardiac arrest severity and prognosis in a preclinical model. BioRxiv [Preprint] 2019. https://doi.org/10.1101/785972. 
191. Wilson RH, Crouzet C, Torabzadeh M, Bazrafkan A, Maki N, Tromberg BJ, et al. High-speed quantitative optical imaging of absolute metabolism in the rat cortex. BioRxiv [Preprint] 2019. https://doi.org/10.1101/786244.

192. Leao AAP. SPREADING DEPRESSION OF ACTIVITY IN THE CEREBRAL CORTEX. J Neurophysiol 1944;7:359-90. https://doi.org/10.1152/jn.1944.7.6.359.

193. Leão AAP. The slow voltage variation of cortical spreading depression of activity. Electroencephalogr Clin Neurophysiol 1951;3:315-21. https://doi.org/10.1016/0013-4694(51)90079-X.

194. Kramer DR, Fujii T, Ohiorhenuan I, Liu CY. Cortical spreading depolarization: Pathophysiology, implications, and future directions. J Clin Neurosci 2016;24:22-7. https://doi.org/10.1016/j. jocn.2015.08.004.

195. Dreier JP. The role of spreading depression, spreading depolarization and spreading ischemia in neurological disease. Nat Med 2011;17:439-47. https://doi.org/10.1038/nm.2333.

196. van Harreveld A, Ochs S. Cerebral impedance changes after circulatory arrest. Am J Physiol 1956;187:180-92. https://doi.org/10. 1152/ajplegacy.1956.187.1.180.

197. Hartings JA, Shuttleworth CW, Kirov SA, Ayata C, Hinzman JM, Foreman B, et al. The continuum of spreading depolarizations in acute cortical lesion development: Examining Leão's legacy. J Cereb Blood Flow Metab 2017;37:1571-94. https://doi.org/10. 1177/0271678X16654495.

198. Dreier JP, Lemale CL, Kola V, Friedman A, Schoknecht K. Spreading depolarization is not an epiphenomenon but the principal mechanism of the cytotoxic edema in various gray matter structures of the brain during stroke. Neuropharmacology 2018;134:189-207. https://doi.org/10.1016/j.neuropharm.2017.09.027.

199. Chung DY, Oka F, Ayata C. Spreading depolarizations: A therapeutic target against delayed cerebral ischemia after subarachnoid hemorrhage. J Clin Neurophysiol 2016;33:196-202. https://doi. org/10.1097/WNP.0000000000000275.

200. Shuttleworth CW, Andrew RD, Akbari Y, Ayata C, Balu R, Brennan KC, et al. Which Spreading Depolarizations Are Deleterious To Brain Tissue? Neurocrit Care 2019. https://doi. org/10.1007/s12028-019-00776-7.

201. Bernard SASA, Gray TWTW, Buist MDMD, Jones BM, Silvester W, Gutteridge G, et al. Treatment of comatose survivors of out-ofhospital cardiac arrest with induced hypothermia. N Engl J Med 2002;11:82-3. https://doi.org/10.1016/s1062-1458(02)00737-7.

202. Peberdy MA, Callaway CW, Neumar RW, Geocadin RG, Zimmerman JL, Donnino M, et al. Part 9: Post-cardiac arrest care: 2010 American Heart Association Guidelines for Cardiopulmonary Resuscitation and Emergency Cardiovascular Care. Circulation 2010;122:768-86. https://doi.org/10.1161/ CIRCULATIONAHA.110.971002.

203. Hypothermia after Cardiac Arrest Study Group. Mild Therapeutic Hypothermia to Improve the Neurologic Outcome after Cardac Arrest. N Engl J Med 2002;346:549-56. https://doi.org/10.1056/ NEJMoa012689.

204. Zeiner A, Holzer M, Sterz F, Schörkhuber W, Eisenburger P, Havel C, et al. Hyperthermia after cardiac arrest is associated with an unfavorable neurologic outcome. Arch Intern Med 2001;161: 2007-12. https://doi.org/10.1001/archinte.161.16.2007.

205. Bro-Jeppesen J, Hassager C, Wanscher M, Søholm H, Thomsen $\mathrm{JH}$, Lippert FK, et al. Post-hypothermia fever is associated with increased mortality after out-of-hospital cardiac arrest. Resuscitation 2013;84:1734-40. https://doi.org/10.1016/j. resuscitation.2013.07.023

206. Leary M, Grossestreuer A V., Iannacone S, Gonzalez M, Shofer FS, Povey C, et al. Pyrexia and neurologic outcomes after therapeutic hypothermia for cardiac arrest. Resuscitation $2013 ; 84$ : 1056-61. https://doi.org/10.1016/j.resuscitation.2012.11.003.
207. Nielsen N, Wetterslev J, Cronberg T, Erlinge D, Gasche Y, Hassager $\mathrm{C}$, et al. Targeted temperature management at $33^{\circ} \mathrm{c}$ versus $36^{\circ} \mathrm{c}$ after cardiac arrest. N Engl J Med 2013;369:2197-206. https://doi.org/10.1056/NEJMoa1310519.

208. Nuzzo A, Peron N, Voicu S, Mégarbane B, Deye N. Targeted temperature management for non-shockable cardiac arrests: The debate must go on. J Thorac Dis 2018;10:1304-7. https://doi.org/ 10.21037/jtd.2018.03.32.

209. Sung G, Bosson N, Kaji AH, Eckstein M, Shavelle D, French WJ, et al. Therapeutic Hypothermia After Resuscitation From a NonShockable Rhythm Improves Outcomes in a Regionalized System of Cardiac Arrest Care. Neurocrit Care 2016;24:90-6. https://doi. org/10.1007/s12028-015-0184-z.

210. Lascarrou JB, Merdji H, Le Gouge A, Colin G, Grillet G, Girardie $\mathrm{P}$, et al. Targeted temperature management for cardiac arrest with nonshockable rhythm. N Engl J Med 2019;381:2327-37. https:// doi.org/10.1056/NEJMoa1906661.

211. Frydland M, Kjaergaard J, Erlinge D, Wanscher M, Nielsen N, Pellis T, et al. Target temperature management of $33^{\circ} \mathrm{C}$ and $36^{\circ} \mathrm{C}$ in patients with out-of-hospital cardiac arrest with initial nonshockable rhythm - A TTM sub-study. Resuscitation 2015;89: 142-8. https://doi.org/10.1016/j.resuscitation.2014.12.033.

212. Thomsen JH, Nielsen N, Hassager C, Wanscher M, Pehrson S, Køber L, et al. Bradycardia during Targeted Temperature Management: An Early Marker of Lower Mortality and Favorable Neurologic Outcome in Comatose Out-of-Hospital Cardiac Arrest Patients*. Crit Care Med 2016;44:308-18. https://doi.org/10.1097/CCM.0000000000001390.

213. Kirkegaard H, Taccone FS, Skrifvars MB, Søreide E. Prolonged targeted temperature management in patients suffering from outof-hospital cardiac arrest. J Thorac Dis 2018;10:E752-4. https:// doi.org/10.21037/jtd.2018.09.78.

214. Kirkegaard H, Søreide E, De Haas I, Pettilä V, Taccone FS, Arus $\mathrm{U}$, et al. Targeted temperature management for 48 vs 24 hours and neurologic outcome after out-of-hospital cardiac arrest: A randomized clinical trial. JAMA - J Am Med Assoc 2017;318:341-50. https://doi.org/10.1001/jama.2017.8978.

215. Cho E, Lee SE, Park E, Kim HH, Lee JS, Choi S, et al. Pilot study on a rewarming rate of $0.15^{\circ} \mathrm{C} / \mathrm{hr}$ versus $0.25^{\circ} \mathrm{C} / \mathrm{hr}$ and outcomes in post cardiac arrest patients. Clin Exp Emerg Med 2019;6:2530. https://doi.org/10.15441/ceem.17.275.

216. Cocchi MN, Boone MD, Giberson B, Giberson T, Farrell E, Salciccioli JD, et al. NIH Public Access 2014;29:365-9. https:// doi.org/10.1177/0885066613491932.Fever.

217. Calabró L, Bougouin W, Cariou A, De Fazio C, Skrifvars M, Soreide E, et al. Effect of different methods of cooling for targeted temperature management on outcome after cardiac arrest: a systematic review and meta-analysis. Crit Care 2019;23. https://doi. org/10.1186/s13054-019-2567-6.

218. De Fazio C, Skrifvars MB, Søreide E, Creteur J, Grejs AM, Kjærgaard J, et al. Intravascular versus surface cooling for targeted temperature management after out-of-hospital cardiac arrest: An analysis of the TTH48 trial. Crit Care 2019;23:1-9. https://doi. org/10.1186/s13054-019-2335-7.

219. Goury A, Poirson F, Chaput U, Voicu S, Garçon P, Beeken T, et al. Targeted temperature management using the "Esophageal Cooling Device" after cardiac arrest (the COOL study): A feasibility and safety study. Resuscitation 2017;121:54-61. https://doi.org/10. 1016/j.resuscitation.2017.09.021.

220. Nordberg P, Taccone FS, Truhlar A, Forsberg S, Hollenberg J, Jonsson M, et al. Effect of Trans-Nasal Evaporative Intra-arrest Cooling on Functional Neurologic Outcome in Out-of-Hospital Cardiac Arrest: The PRINCESS Randomized Clinical Trial. Jama 2019;321:1677-85. https://doi.org/10.1001/jama.2019.4149.

221. Cronberg T, Lilja G, Horn J, Kjaergaard J, Wise MP, Pellis T, et al. Neurologic function and health-related quality of life in patients 
following targeted temperature management at $33^{\circ} \mathrm{C}$ vs $36^{\circ} \mathrm{C}$ after out-of-hospital cardiac arrest a randomized clinical trial. JAMA Neurol 2015;72:634-41. https://doi.org/10.1001/jamaneurol. 2015.0169

222. Lilja G, Nielsen N, Friberg H, Horn J, Kjaergaard J, Nilsson F, et al. Cognitive Function in survivors of out-of-hospital cardiac arrest after target temperature management at $33^{\circ} \mathrm{C}$ Versus $36^{\circ} \mathrm{C}$. Circulation 2015;131:1340-9. https://doi.org/10.1161/CIRCULATIONAHA. 114.014414

223. Hu HJ, Song M. Disrupted Ionic Homeostasis in Ischemic Stroke and New Therapeutic Targets. J Stroke Cerebrovasc Dis 2017;26:270619. https://doi.org/10.1016/j.jstrokecerebrovasdis.2017.09.011.

224. King ZA, Sheth KN, Kimberly WT, Simard JM. Profile of intravenous glyburide for the prevention of cerebral edema following large hemispheric infarction: Evidence to date. Drug Des Devel Ther 2018;12:2539-52. https://doi.org/10.2147/DDDT.S150043.

225. Sheth KN, Petersen NH, Cheung K, Elm JJ, Hinson HE, Molyneaux BJ, et al. Long-term outcomes in patients aged $\geq 70$ years with intravenous glyburide from the Phase II GAMES-RP study of large hemispheric infarction an exploratory analysis. Stroke 2018;49:1457-63. https://doi.org/10.1161/STROKEAHA. 117.020365 .

226. Kang Y-J, Tian G, Bazrafkan A, Farahabadi MH, Azadian M, Abbasi $\mathrm{H}$, et al. Recovery from coma post-cardiac arrest is dependent on the orexin pathway. J Neurotrauma 2017:neu.2016.4852. https://doi.org/10.1089/neu.2016.4852.

227. Modi HR, Wang Q, Sahithi GD, Sherman D, Greenwald E, Savonenko A V., et al. Intranasal post-cardiac arrest treatment with orexin-A facilitates arousal from coma and ameliorates neuroinflammation. PLoS One 2017;12. https://doi.org/10.1371/journal. pone. 0182707 .

228. Shaik JSB, Poloyac SM, Kochanek PM, Alexander H, Tudorascu DL, Clark RSB, et al. 20-Hydroxyeicosatetraenoic Acid Inhibition by HET0016 Offers Neuroprotection, Decreases Edema, and Increases Cortical Cerebral Blood Flow in a Pediatric Asphyxial Cardiac Arrest Model in Rats. J Cereb Blood Flow Metab 2015;35:1757-63. https://doi.org/10.1038/jcbfm.2015.117.

229. Quaegebeur A, Segura I, Schmieder R, Verdegem D, Decimo I, Bifari F, et al. Deletion or inhibition of the oxygen sensor PHD1 protects against ischemic stroke via reprogramming of neuronal metabolism. Cell Metab 2016;23:280-91. https://doi.org/10.1016/ j.cmet.2015.12.007.

230. Vrselja Z, Daniele SG, Silbereis J, Talpo F, Morozov YM, Sousa AMM, et al. Restoration of brain circulation and cellular functions hours post-mortem. Nature 2019;568:336-43. https://doi.org/10. 1038/s41586-019-1099-1.

231. Reardon S. Pig brains kept alive outside body for hours after death. Nature 2019;568:283-4. https://doi.org/10.1038/d41586-01901216-4.

232. Li W, Yang S. Targeting oxidative stress for the treatment of ischemic stroke: Upstream and downstream therapeutic strategies. Brain Circ 2016;2:153. https://doi.org/10.4103/2394-8108. 195279.

233. Forrester SJ, Kikuchi DS, Hernandes MS, Xu Q, Griendling KK. Reactive oxygen species in metabolic and inflammatory signaling. Circ Res 2018;122:877-902. https://doi.org/10.1161/ CIRCRESAHA.117.311401

234. Rabadi MH, Kristal BS. Effect of vitamin C supplementation on stroke recovery: a case-control study. Clin Interv Aging 2007;2: 147-51. https://doi.org/10.2147/ciia.2007.2.1.147.

235. Firuzi O, Miri R, Tavakkoli M, Saso L. Antioxidant Therapy: Current Status and Future Prospects. Curr Med Chem 2012;18: 3871-88. https://doi.org/10.2174/092986711803414368.

236. Nomani F, Kamran Kamal A. Citicoline in the treatment of acute ischaemic stroke: An international, randomized, multicentre, placebo-controlled study (ICTUS trial)Is the use of Citicoline is beneficial for acute ischaemic stroke? J Pak Med Assoc 2013;63: 1445.

237. Diener HC, Lees KR, Lyden P, Grotta J, Davalos A, Davis SM, et al. NXY-059 for the treatment of acute stroke: Pooled analysis of the SAINT I and II trials. Stroke 2008;39:1751-8. https://doi. org/10.1161/STROKEAHA.107.503334.

238. Teixeira G, Szyndralewiez C, Molango S, Carnesecchi S, Heitz F, Wiesel P, et al. Therapeutic potential of NADPH oxidase 1/4 inhibitors. Br J Pharmacol 2017;174:1647-69. https://doi.org/10. 1111/bph.13532.

239. Vereczki V, Martin E, Rosenthal RE, Hof PR, Hoffman GE, Fiskum G. Normoxic resuscitation after cardiac arrest protects against hippocampal oxidative stress, metabolic dysfunction, and neuronal death. J Cereb Blood Flow Metab 2006;26:821-35. https://doi.org/10.1038/sj.jcbfm.9600234.

240. Allen BS, Ko Y, Buckberg GD, Tan Z. Studies of isolated global brain ischaemia: III. Influence of pulsatile flow during cerebral perfusion and its link to consistent full neurological recovery with controlled reperfusion following $30 \mathrm{~min}$ of global brain ischaemia. Eur J Cardio-Thoracic Surg 2012;41:1147-54. https://doi.org/10. 1093/ejcts/ezr317.

241. Dell'Anna AM, Lamanna I, Vincent JL, Taccone FS. How much oxygen in adult cardiac arrest? Crit Care 2014;18. https://doi.org/ 10.1186/s13054-014-0555-4.

242. Jakkula P, Reinikainen M, Hästbacka J, Pettilä V, Loisa P, Karlsson S, et al. Targeting low- or high-normal Carbon dioxide, Oxygen, and Mean arterial pressure After Cardiac Arrest and REsuscitation: Study protocol for a randomized pilot trial. Trials 2017;18:1-9. https://doi.org/10.1186/s13063-017-2257-0.

243. Sekhon MS, Griesdale DE. Individualized perfusion targets in hypoxic ischemic brain injury after cardiac arrest. Crit Care 2017;21:1-5. https://doi.org/10.1186/s13054-017-1832-9.

244. Mickel HS, Vaishnav YN, Kempski O, Lubitz D Von, Weiss JF, Feuerstein G. Breathing 100\% oxygen after global brain ischemia in mongolian gerbils results hi increased lipid peroxidation and increased mortality. Stroke 1987;18:426-30. https://doi.org/10. 1161/01.STR.18.2.426.

245. Liu Y, Rosenthal RE, Haywood Y, Miljkovic-Lolic M, Vanderhoek JY, Fiskum G. Normoxic ventilation after cardiac arrest reduces oxidation of brain lipids and improves neurological outcome. Stroke 1998;29:1679-86. https://doi.org/10.1161/01. STR.29.8.1679.

246. Jakkula P, Reinikainen M, Hästbacka J, Loisa P, Tiainen M, Pettilä $\mathrm{V}$, et al. Targeting two different levels of both arterial carbon dioxide and arterial oxygen after cardiac arrest and resuscitation: a randomised pilot trial. Intensive Care Med 2018;44:2112-21. https://doi.org/10.1007/s00134-018-5453-9.

247. Kim B, Park I, Lee JH, Kim S, Lee MJ, Jo YH. Effect of Electrical Vagus Nerve Stimulation on Cerebral Blood Flow and Neurological Outcome in Asphyxial Cardiac Arrest Model of Rats. Neurocrit Care 2019;30:572-80. https://doi.org/10.1007/ s12028-018-0640-7.

248. Allen BS, Ko Y, Buckberg GD, Tan Z. Studies of isolated global brain ischaemia: II. Controlled reperfusion provides complete neurologic recovery following $30 \mathrm{~min}$ of warm ischaemia - the importance of perfusion pressure. Eur J Cardiothorac Surg 2012;41: 1147-54. https://doi.org/10.1093/ejcts/ezr317.

249. Gao C-J, Niu L, Ren P-C, Wang W, Zhu C, Li Y-Q, et al. Hypoxic preconditioning attenuates global cerebral ischemic injury following asphyxial cardiac arrest through regulation of delta opioid receptor system. Neuroscience 2012;202:352-62. https://doi.org/ 10.1016/j.neuroscience.2011.11.060.

250. Jensen HA, Loukogeorgakis S, Yannopoulos F, Rimpiläinen E, Petzold A, Tuominen H, et al. Remote Ischemic Preconditioning Protects the Brain Against Injury After Hypothermic Circulatory 
Arrest. Circulation 2011;123:714-21. https://doi.org/10.1161/ CIRCULATIONAHA.110.986497.

251. Pérez-Pinzón MA, Xu GP, Dietrich WD, Rosenthal M, Sick TJ. Rapid preconditioning protects rats against ischemic neuronal damage after 3 but not 7 days of reperfusion following global cerebral ischemia. J Cereb Blood Flow Metab 1997;17:175-82. https://doi.org/10.1097/00004647-199702000-00007.

252. Gidday JM. Cerebral preconditioning and ischaemic tolerance. Nat Rev Neurosci 2006;7:437-48. https://doi.org/10.1038/ nrn1927.

253. Dharap A, Vemuganti R. Ischemic pre-conditioning alters cerebral microRNAs that are upstream to neuroprotective signaling pathways. J Neurochem 2010;113:1685-91. https://doi.org/10.1111/j. 1471-4159.2010.06735.x.

254. Correia SC, Carvalho C, Cardoso S, Santos RX, Santos MS, Oliveira CR, et al. Mitochondrial preconditioning: A potential neuroprotective strategy. Front Aging Neurosci 2010;2:1-13. https://doi.org/10.3389/fnagi.2010.00138.

255. Constantino LC, Tasca CI, Boeck CR. The role of NMDA receptors in the development of brain resistance through pre- and postconditioning. Aging Dis 2014;5:430-42. https://doi.org/10. 14336/AD.2014.0500430.

256. Zhao H, Sapolsky RM, Steinberg GK. Interrupting reperfusion as a stroke therapy: Ischemic postconditioning reduces infarct size after focal ischemia in rats. J Cereb Blood Flow Metab 2006;26: 1114-21. https://doi.org/10.1038/sj.jcbfm.9600348.

257. Ren C, Yan Z, Wei D, Gao X, Chen X, Zhao H. Limb remote ischemic postconditioning protects against focal ischemia in rats. Brain Res 2009;1288:88-94. https://doi.org/10.1016/j.brainres. 2009.07.029.

258. Meng R, Asmaro K, Meng L, Liu Y, Ma C, Xi C, et al. Upper limb ischemic preconditioning prevents recurrent stroke in intracranial arterial stenosis. Neurology 2012;79:1853-61. https://doi.org/10. 1212/WNL.0b013e318271f76a.
259. Mitchell HM, White DM, Domowicz MS, Kraig RP. Cold preconditioning neuroprotection depends on TNF- $\alpha$ and is enhanced by blockade of interleukin-11. J Neurochem 2011;117:187-96. https://doi.org/10.1111/j.1471-4159.2010.07103.x.

260. Yang Q, Guo M, Wang X, Zhao Y, Zhao Q, Ding H, et al. Ischemic preconditioning with a ketogenic diet improves brain ischemic tolerance through increased extracellular adenosine levels and hypoxia-inducible factors. Brain Res 2017;1667:11-8. https:// doi.org/10.1016/j.brainres.2017.04.010.

261. Zhang J, Zhang W, Gao X, Zhao Y, Chen D, Xu N, et al. Preconditioning with partial caloric restriction confers long-term protection against grey and white matter injury after transient focal ischemia. J Cereb Blood Flow Metab 2019;39:1394-409. https:// doi.org/10.1177/0271678X18785480.

262. Azadian M, Tian G, Bazrafkan A, Maki N, Rafi M, Desai M, et al. Overnight caloric restriction prior to cardiac arrest and resuscitation leads to improved survival and neurological outcome in a rodent model. BioRxiv 2019. https://doi.org/10.1101/786871.

263. Bus1 KM, Greer DM. Hypoxic-ischemic brain injury: Pathophysiology, neuropathology and mechanisms. NeuroRehabilitation 2010;26:5-13. https://doi.org/10.3233/ NRE-2010-0531.

264. Rossetti AO, Rabinstein AA, Oddo M. Neurological prognostication of outcome in patients in coma after cardiac arrest. Lancet Neurol 2016;15:597-609. https://doi.org/10.1016/S14744422(16)00015-6.

265. Böttiger BW, Schneider A, Popp E. Number needed to treat = six: Therapeutic hypothermia following cardiac arrest - An effective and cheap approach to save lives. Crit Care 2007;11:4-5. https:// doi.org/10.1186/cc6100.

Publisher's Note Springer Nature remains neutral with regard to jurisdictional claims in published maps and institutional affiliations. 